\title{
Efferent Inputs Are Required for Normal Function of Vestibular Nerve Afferents
}

\author{
Vishal Raghu, ${ }^{1,2}$ Richard Salvi, ${ }^{1,2}$ and ${ }^{-S}$ Soroush G. Sadeghi ${ }^{1,2}$ \\ ${ }^{1}$ Department of Communicative Disorders and Sciences, Center for Hearing and Deafness, and ${ }^{2}$ Neuroscience Program, State University of New York at \\ Buffalo, Buffalo, New York 14214
}

A group of vestibular afferent nerve fibers with irregular-firing resting discharges are thought to play a prominent role in responses to fast head movements and vestibular plasticity. We show that, in C57BL/6 mice (either sex, 4-5 weeks old), normal activity in the efferent vestibular pathway is required for function of these irregular afferents. Thermal inhibition of efferent fibers results in a profound inhibition of irregular afferents' resting discharges, rendering them inadequate for signaling head movements. In this way, efferent inputs adjust the contribution of the peripheral irregular afferent pathway that plays a critical role in peripheral vestibular signaling and plasticity.

Key words: afferent; efferent; irregular; thermal inhibition; vestibular nerve

\section{Significance Statement}

Vestibular end organs in the inner ear receive efferent inputs from the brainstem. Previously, electrical stimulation of efferents was linked to an increase in resting discharges of afferents and a decrease in their sensitivities. Here, we show that localized thermal inhibition of unmyelinated efferents results in a significant decrease in the activity of afferent nerve fibers, particularly those with irregular resting discharges implicated in responses to fast head movements and vestibular compensation. Thus, by upregulating and downregulating of afferent firing, particularly irregular afferents, efferents adjust neural activity sensitive to rapid head movements. These findings support the notion that peripheral vestibular end organs are not passive transducers of head movements and their sensory signal transmission is modulated by efferent inputs.

\section{Introduction}

The vestibular system provides information critical for maintaining stable balance and eye movements during normal activities. Vestibular dysfunction, which affects $35 \%$ of Americans $>40$ years of age, disrupts routine daily activities and results in significant health-related costs (Agrawal et al., 2013). Previous studies have shown that vestibular information is carried in two channels: a phasic channel that encodes high-frequency head movements; and a tonic, broadband channel that provides general

\footnotetext{
Received Jan. 28, 2019; revised June 28, 2019; accepted July 1, 2019

Author contributions: V.R., R.S., and S.G.S. designed research; V.R. and S.G.S. performed research; V.R. and S.G.S. analyzed data; V.R., R.S., and S.G.S. edited the paper;V.R., R.S., and S.G.S. wrote the paper; S.G.S. wrote the first draft of the paper.

This work was supported by National Institute on Deafness and Other Communication Disorders Grant R03 DC015091 and American Otological Society Research Grant to S.G.S., and National Institutes of Health Grant R01 DC014693 to R.S. The datasets generated during and/or analyzed during the current study are available from the corresponding author on reasonable request. We thank Dr. Kathleen Cullen and Dr. Robert Burkard for comments on the manuscript; Eric Tyler and Julia Murak for helping in the early stages of the study; and the reviewers of the Journal of Neuroscience for insightful and detailed comments that helped improve the manuscript.

The authors declare no competing financial interests.

Correspondence should be addressed to Soroush G. Sadeghi at soroushs@buffalo.edu.

https://doi.org/10.1523/JNEUROSCI.0237-19.2019

Copyright $\odot 2019$ the authors
}

information about head movements (Sadeghi et al., 2007b; Beraneck and Straka, 2011; Eatock and Songer, 2011). In the vestibular periphery, neurons with regular resting discharge rates form the tonic channel, and those with irregular discharge rates form the phasic pathway. These afferents innervate two types of hair cells: cylindrical Type II hair cells and flask-shaped Type I hair cells (Fernández et al., 1995). Afferents with bouton terminals that contact only Type II hair cells have highly regular resting discharges, and those with calyx terminals that contact only Type I hair cells have highly irregular resting discharges (Goldberg et al., 1992). However, most regular and irregular afferents receive inputs from both Type I and Type II hair cells.

The vestibular organs of almost every vertebrate also receive a prominent efferent innervation that originates from a few hundred neurons located in the brainstem bilaterally (Gacek and Lyon, 1974; Goldberg and Fernández, 1980). Each efferent axon branches profusely in the vestibular neuroepithelium (Purcell and Perachio, 1997) to innervate Type II hair cells and afferent boutons and calyx terminals (Goldberg et al., 1990a). Recent studies have shown that cochlear and vestibular hair cells express $\alpha 9 \alpha 10$ AChR (Hiel et al., 1996; Katz et al., 2004) that has an inhibitory effect (Glowatzki and Fuchs, 2000; Wersinger and 
Fuchs, 2011; Zhou et al., 2013; Poppi et al., 2018). On the other hand, calyx terminals express excitatory $\alpha 4 \beta 2$ or $\alpha 6 \beta 2$ AChR (Holt et al., 2015). With efferent stimulation in mammals, the sum of the above effects results in an increase in the resting discharge of afferents and a decrease in their sensitivity (Goldberg and Fernández, 1980), an effect that is directly related to the irregularity of resting discharge (Goldberg and Fernández, 1980; Plotnik et al., 2002; Sadeghi et al., 2009a). The above findings suggest that efferents might function to modify the firing properties of afferents. This notion is supported by vestibular defects in two mouse models with efferent dysfunction. Calcitonin generelated protein (Luebke et al., 2014) and $\alpha 9$ (Hübner et al., 2015, 2017) KO mice show abnormalities in the development of the vestibulo-ocular reflex response as well as its adaptation and compensation. To date, no studies have attempted to silence the efferents to observe their direct effect on the function of afferents.

In the present study, we investigated the hypothesis that increasing the temperature around the axons of efferents would reversibly inhibit them, providing the means for studying the absence of their function directly. The rationale for these studies is based on the fact that efferent (but not afferent) fibers are thin and unmyelinated or lightly myelinated (Luebke et al., 2014; Holt et al., 2015; Jordan et al., 2015) and that such fibers could be inhibited by heat (Wakabayashi et al., 1993; Tsuchiya et al., 1994; Duke et al., 2012, 2013; Lothet et al., 2017). To test this hypothesis, we recorded from the vestibular nerve afferent fibers to quantify the effect of efferent inhibition via heating with LEDcoupled optical fibers (OFs) or warm saline application. We observed that a rise in temperature over the vestibular nerve axons or brainstem midline (i.e., commissural efferents) resulted in an inhibition of afferents. Importantly, the magnitude of afferent inhibition was in direct relation to the irregularity of afferent resting discharges. Our results suggest that efferent inputs play an important role in adjusting the resting discharge rates of afferents, particularly those of irregular fibers that encode rapid head movements and are required for normal vestibular adaptation and compensation.

\section{Materials and Methods}

Surgery. Recordings were made from 97 C57BL/6 mice of either sex between the ages of P28 and P35. Mice were deeply anesthetized by intraperitoneal injection of ketamine $(80 \mathrm{mg} / \mathrm{kg})$ and xylazine $(10 \mathrm{mg} / \mathrm{kg})$. Once unresponsive to toe pinch, a mouse was held in a stereotaxic frame on top of a turntable. The bone was exposed through a midline incision of the skin on top of the head, and a craniotomy was performed in the lateral part of the parietal bone. The lateral portion of the cerebellum was then carefully aspirated, avoiding major blood vessels, until the Scarpa's ganglion and the eighth nerve were exposed. The level of sedation was tested at $30-45 \mathrm{~min}$ intervals via toe pinch, and additional doses of anesthesia ( $30 \%-50 \%$ of the original dose) were administered if necessary. All procedures were approved by the Institutional Animal Care and Use Committee at the University at Buffalo and performed in accordance with National Institutes of Health guidelines.

Neural recording and data acquisition. Single-unit extracellular recordings from the vestibular nerve were performed using glass electrodes with impedances of $\sim 20 \mathrm{M} \Omega$. Electrodes were fabricated from borosilicate glass capillaries with $1 \mathrm{~mm}$ outer diameters (World Precision Instruments) using a P-1000 filament puller (Sutter Instruments) and were filled with $3 \mathrm{~m} \mathrm{NaCl}$ solution. The electrode was driven by a single-axis micromanipulator (MO-10, Narishige) and positioned over the nerve, close to the ganglion under direct visualization through a surgical microscope (Carl Zeiss). Only vestibular afferents with spontaneous resting discharge were recorded. In a few cases, once the unit was isolated, animals were rotated by the turntable. This was used to approximately identify whether these afferents were innervated by the horizontal canal, vertical canals, or otolith organs (Sadeghi et al., 2007a, 2009a). The velocity of the rotational movement was measured by a velocity sensor (Diversified Technical Systems) attached to the table. Signals from the nerve were amplified and bandpass filtered between $300 \mathrm{~Hz}$ and $1 \mathrm{kHz}$ (EXT-02B amplifier, npi). An external auditory speaker was used to discern the activity of neurons. In addition, the voltage from the microelectrode was digitized with a 16-bit A/D converter at a sampling rate of 25 $\mathrm{kHz}$ (micro1401, CED). All signals were then recorded on a PC for offline analysis.

Optical stimulation and temperature measurement. Optical stimulation was provided by LED-coupled OFs (Prizmatix) that provided blue (460 $\mathrm{nm}, 75 \mathrm{~mW}$ at the tip) or red $(655 \mathrm{~nm}, 40 \mathrm{~mW}$ at the tip) light. A single-mode fiberoptic cable with a $500 \mu \mathrm{m}$ diameter (NA 0.63) was positioned $\sim 0.5 \mathrm{~mm}$ away from the nerve or ganglion under direct visual observation. The duration and timing of light pulses were controlled by TTL pulses that were also recorded by micro1401. Intensity of the light could be adjusted accurately by a 10-turn potentiometer.

Temperature was measured by a thermocouple probe (CN-7823, Omega Engineering) with a diameter of $0.5 \mathrm{~mm}$. The tip of the probe was inserted into the nerve directly below the $\mathrm{OF}$, to record the temperature at the site of stimulus or at other positions along the nerve to record the spread of heat to those areas. Measured values were transferred to the computer and recorded using CN7-A software (Omega Engineering) and saved for further analysis. Due to the exposure through the craniotomy, the temperature of the vestibular nerve and ganglion was typically similar to room temperature at the beginning of experiments. The net energy absorbed $(Q)$ during changes in temperature can be represented as $Q=m c \Delta T$, where $m$ is the mass of the affected volume, $c$ is its specific heat capacity, and $\Delta T$ is the net change in temperature. Given that $m$ and $c$ are constants, we preferably used $\Delta T\left({ }^{\circ} \mathrm{C}\right.$, as measured by the probe) rather than converting it to $Q$ (joules) for our analysis.

Thermal stimulation by application of warm saline. To test the effect of heating or cooling, warm or cold solutions were applied inside the craniotomy through a tube with a $\sim 0.5 \mathrm{~mm}$ tip, positioned on the side of the craniotomy opening, and excess solution was also suctioned at the edge of the craniotomy. The solution was heated using an inline solution heater (SH-27B, Warner Instruments). The final temperature was set by a controller (TC-324C, Warner Instruments) that received feedback from its sensor positioned near the application tip; this held the temperature relatively constant at the specified set values (i.e., temperature plateaus) with only minor oscillations of $<0.5^{\circ} \mathrm{C}$ per minute. Temperatures thus obtained could be recorded in real time via the $\mathrm{A} / \mathrm{D}$ converter. In a few cases, we compared the difference between the actual temperature measured by another sensor in the nerve and the one providing feedback to the controller and observed a constant difference of $<0.6^{\circ} \mathrm{C}$ due to loss of heat in the craniotomy. Values presented in the text are those measured by the controller sensor and were not corrected. In most experiments, flow rate was adjusted by a pump (P720 peristaltic pump, Instech), which affected the rate of change in temperature as well as the final steady-state temperatures. The combination of different rates of application and set temperatures allowed us to achieve temperature profiles with different dynamics. From all the different profiles tested, we used three that were different in both the rate of rise of temperature $(\mathrm{dT} / \mathrm{dt})$ and the final steady-state temperature $(\mathrm{T})$. Specifically, we used combinations of flow rates $(\mu \mathrm{l} / \mathrm{s})$ and set temperatures $\left({ }^{\circ} \mathrm{C}\right)$ (rate/temperature) as follows: 17/38 (low), 17/43 (medium), and 23/48 (high). The three profiles (see Fig. $7 \mathrm{~A}$ ) had peak dT/dt values of $0.06 \pm 0.01^{\circ} \mathrm{C}, 0.1 \pm$ $0.003^{\circ} \mathrm{C}$, and $0.16 \pm 0.005^{\circ} \mathrm{C} / \mathrm{s}$ and temperature plateaus of $\sim 26.5^{\circ} \mathrm{C}$, $29.5^{\circ} \mathrm{C}$, and $32.5^{\circ} \mathrm{C}$, respectively. This allowed us to investigate the effect of $\mathrm{dT} / \mathrm{dt}$ and change in $\mathrm{T}$ on the firing rate of afferents. The temperature plateau was held for at least $100 \mathrm{~s}$, and the return to room temperature was uncontrolled and achieved by turning the pump and heater off. Between each profile, we waited for 5-10 min for the temperature to return to room temperature $\left(22^{\circ} \mathrm{C}-24^{\circ} \mathrm{C}\right)$. As control for any effects due to the solution itself or mechanical effects due to the flow of the solution, we applied room temperature saline in a few sessions and observed no effect on firing rates of afferents.

Data analysis. Data were imported into MATLAB (The MathWorks) programming environment for analysis. Spike times were triggered by 
A
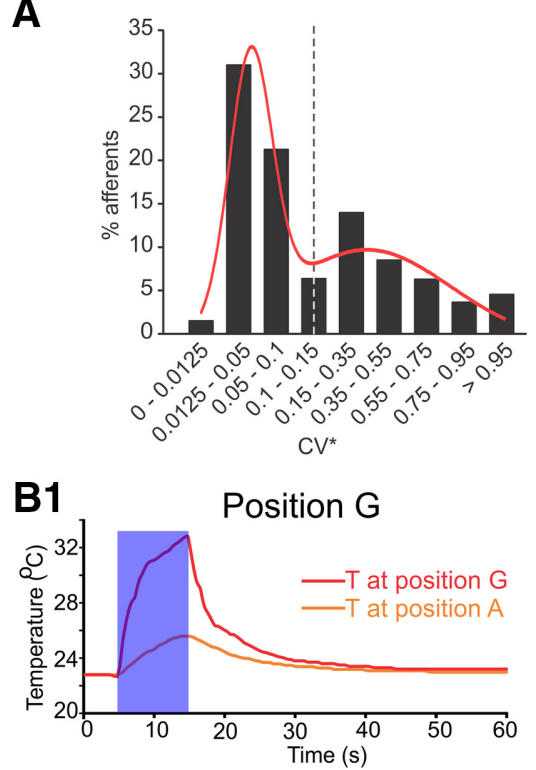

\section{B2}

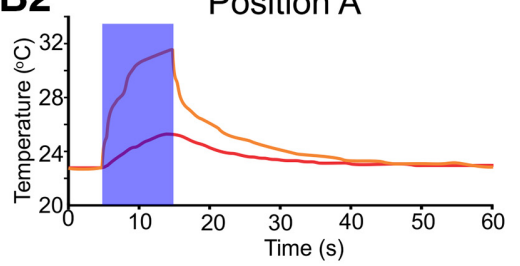

\section{D}

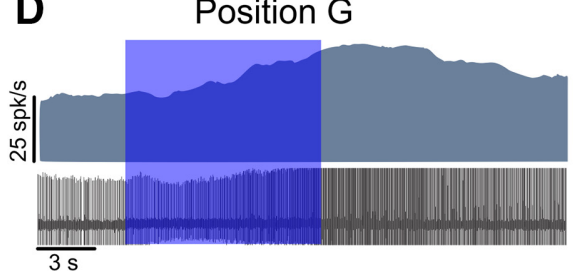

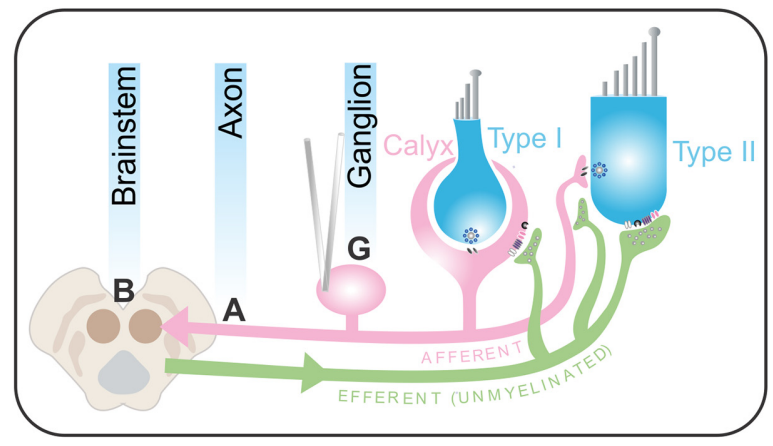
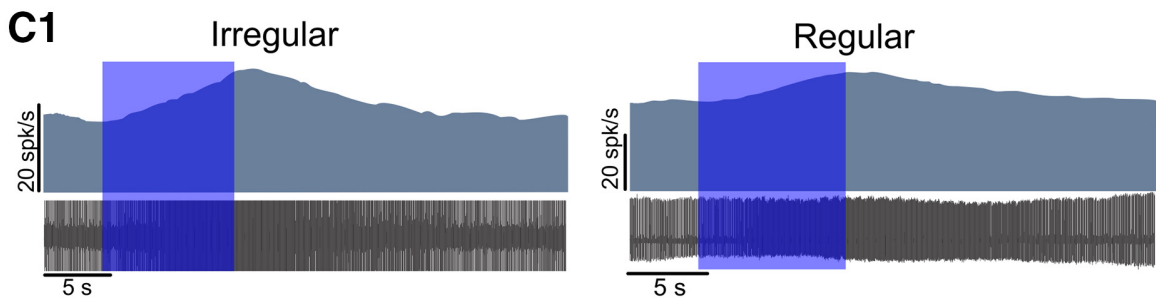

C2
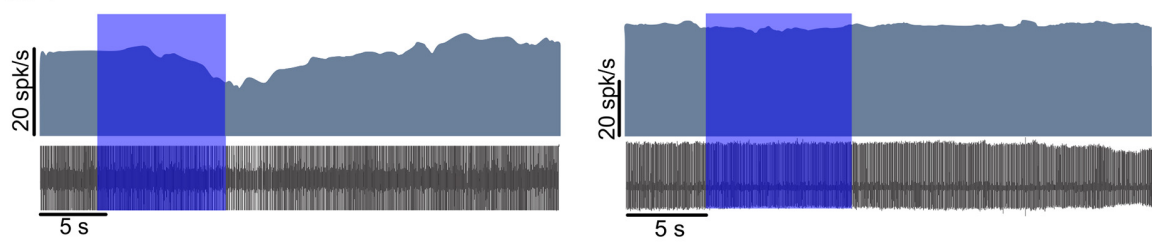

Between positions $\mathrm{A}$ and $\mathrm{G}$

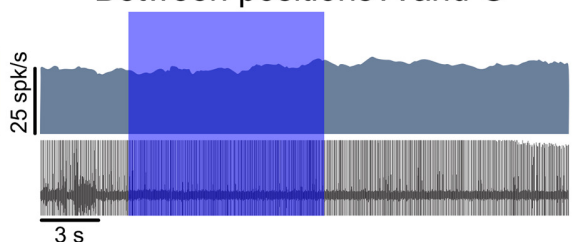

Figure 1. Optothermal stimulation affects vestibular nerve afferent resting discharge in WT mice. A, Bimodal distribution of the normalized CV (CV*) for all the recorded afferents was fit using a sum of two Gaussians $\left(R^{2}=0.87\right)$. Dashed line indicates the criteria of $\mathrm{CV}^{*}$ of $0.1-0.15$ for separation of regular and irregular afferents. $\boldsymbol{B}, 0 \mathrm{~F}$ positioned over the ganglion $(\boldsymbol{B} 1$, position $\mathrm{G})$ or nerve axons ( $\boldsymbol{B 2}$, position A), as shown in the schematic resulted in local temperature change with little spread. Recording electrode was positioned near the ganglion. Blue box represents the duration of optothermal stimulation. Top schematic represents different positions of the OF used in our experiments. C, The effect of stimulation was dependent on OF position and afferent type. C1, Excitatory response in representative regular and irregular afferents with the $\mathrm{OF}$ in position $\mathrm{G}$. $\mathbf{C}$, When the $\mathrm{OF}$ was moved to position $\mathrm{A}$, it had inhibitory effect on the same irregular fiber and no effect on the regular fiber. $D$, Example recording showing no effect with the $0 F$ placed between position $G$ (excitatory response) and position $A$ (inhibitory response).

setting a voltage threshold. The firing rate was represented using a spike density function in which a Gaussian was convolved with the binary matrix of spike times (Cullen et al., 1996). Afferents were divided into two groups based on the regularity of their resting discharge by calculating the coefficient of variation $(\mathrm{CV})$ from at least $10 \mathrm{~s}$ of the resting discharge. Because of the dependence of $\mathrm{CV}$ on the interspike interval, it was normalized by calculating the $\mathrm{CV}$ at a mean interspike interval of 15 ms $\left(\mathrm{CV}^{\star}\right)$ (Goldberg et al., 1984; Lasker et al., 2008). For gain analysis of thermal stimulation, temperature traces were filtered using Fourier fits of 8 terms $\left(R^{2}=1\right)$. Linear gains for $\Delta \mathrm{T}$ and $\mathrm{dT} / \mathrm{dt}$ were calculated by using the polyfit function in MATLAB to yield polynomial fits of the following form:

$$
\text { est }=c+a(\Delta \mathrm{T})+b(\mathrm{dT} / \mathrm{dt})
$$

where est is estimation of firing rate, $c$ is a constant representing the resting discharge, and $a$ and $b$ are the respective gains of $\Delta \mathrm{T}$ and $\mathrm{dT} / \mathrm{dt}$. Values of $a-c$ were optimized to find the best fit to the recorded firing rate, having the highest $R^{2}$. For each afferent, polynomials with three or two parameters (i.e., $a$ or $b$ set to 0 ) were used to find the smallest number of parameters required to find the best estimation.
Statistical analysis. Data are described as mean \pm SE. Statistical tests were performed using Excel (Microsoft) or Prism (GraphPad) software. Student's $t$ tests were used to compare the average of two measured parameters. For comparisons of more than two conditions, one-way ANOVA with Tukey's post hoc test was used. Level of statistical significance was set at $\alpha=0.05$.

\section{Results}

Recordings were made from 328 vestibular nerve afferent fibers that had spontaneous (resting) discharges. The electrode was positioned under direct visualization, over the proximal part of the nerve near the vestibular ganglion. The average resting discharge was $20 \pm 0.6 \mathrm{spikes} / \mathrm{s}$, with a range of $1-75$ spikes/s. A normalized $\mathrm{CV}\left(\mathrm{CV}^{*}\right)$ was calculated as a measure of regularity of discharge with values in the range of $0.009-1.46$. Similar to previous studies and based on the $\mathrm{CV}^{\star}$ of the recorded afferents, which showed a bimodal distribution with modes separated by an order of magnitude (Fig. $1 A$ ), a $\mathrm{CV}^{\star}$ of 0.1 was used to divide afferents into regular and irregular groups, with $\sim 50 \%$ of afferents in each 
A1

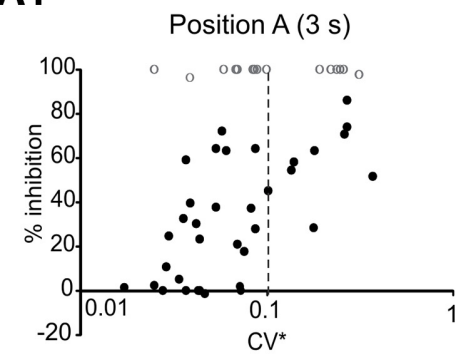

B1

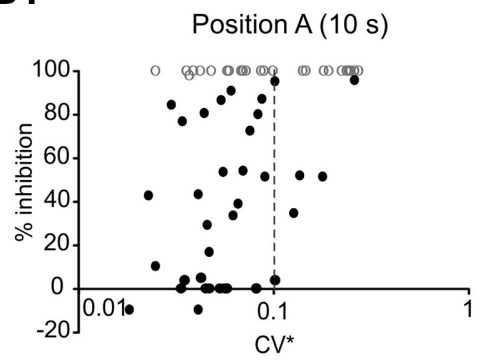

C

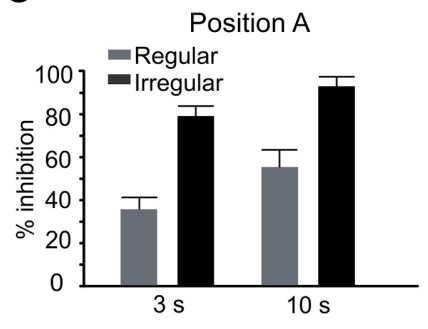

B2

A2

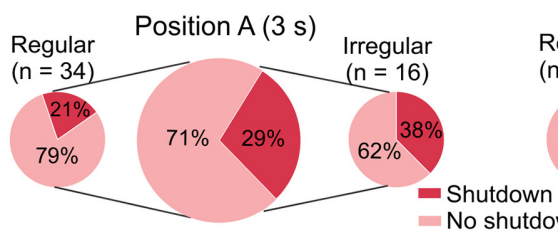

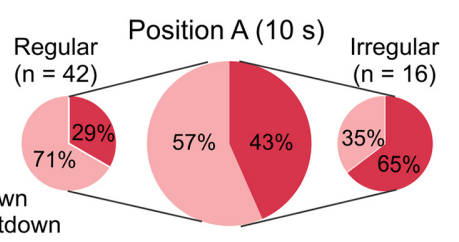

D

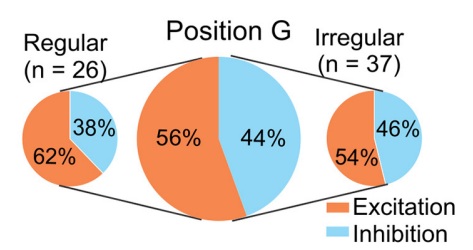

Figure 2. Responses of population of afferents to optothermal stimulation. $A$, Responses to $3 \mathrm{~s}$ stimulation and discharge regularity based on the $\mathrm{CV}^{*}$. $\mathrm{ACV}^{*}$ of 0.1 (dashed line) was considered the cutoff between regular and irregular afferents. Afferents that were inhibited by $>95 \%$ were considered to be shut down (fully inhibited) and are represented by empty circles $(\boldsymbol{A} \mathbf{1})$. 0 f the afferents that were not shut down, 27 were regular and 10 were irregular ( $\boldsymbol{A} 2)$. $\boldsymbol{B}$, Responses to $3 \mathrm{~s} \mathrm{stimulation} \mathrm{and} \mathrm{discharge} \mathrm{regularity} \mathrm{based} \mathrm{on} \mathrm{the} \mathrm{CV}^{*}(\boldsymbol{B} 1)$. There were a few regular afferents with increases in resting rate (points below the $x$ axis) and higher number of $100 \%$ inhibitions compared with $3 \mathrm{~s} \mathrm{stimulation.} 0$ f the afferents that were not shut down, 30 were regular and 5 were irregular (B2). C, Irregular afferents showed larger mean inhibition compared with regular afferents for $3 \mathrm{~s}$ ( $t$ test, $p=0.0007$ ) and $10 \mathrm{~s}$ ( $t$ test, $p=0.0003)$ stimulation. $\boldsymbol{D}$, When located at position $\mathrm{G}$, most afferents were excited with optothermal stimulation, the majority of which were regular fibers (excitation: 23 regular and 12 irregular; inhibition: 14 regular and 14 irregular).

group (Goldberg et al., 1984; Lasker et al., 2008; Sadeghi et al., 2009b; Yu et al., 2012).

\section{Differential effect of heat on vestibular afferents}

We delivered blue light ( $460 \mathrm{~nm}$, maximum power: $75 \mathrm{~mW}$ ) via an LED-coupled OF with a duty cycle of $90 \%$ in one of two locations: over the vestibular ganglion, located just outside the bone at the base of the superior canal (henceforth, position G; Fig. 1, schematic); or over the distal part of the vestibular nerve where the axons of the afferents and efferents are located (position A). Temperature was measured using a thermocouple sensor with the tip positioned in the nerve or ganglion region under the OF. At each position (A or G), with a $10 \mathrm{~s}$ stimulus at maximum power, the temperature increased from room temperature $\left(\sim 22^{\circ} \mathrm{C}\right)$ to $\sim 33^{\circ} \mathrm{C}$, with negligible spread of heat to the other position (Fig. $1 B 1, B 2 ; \sim 2^{\circ} \mathrm{C}$ change). With the LED off, the temperature returned to room temperature in $<1 \mathrm{~min}$. Optothermal stimulation at position $\mathrm{G}$ affects afferent cell bodies in the ganglion as well as efferent fibers passing through the ganglion. Typically, we observed a reversible increase in the resting discharge of afferents (Fig. 1C1). This was expected based on previous reports showing an increase in the activity of vestibular ganglion neurons with heat (Rajguru et al., 2011). While recording from the same fibers, the OF was moved from position $\mathrm{G}$ to position A, targeting the nerve bundle containing afferent and efferent fibers. An increase in temperature in position A resulted in a reversible inhibition of the irregular afferent but had no effect on the regular fiber (Fig. 1C2). Because electrical or rotational stimulation of efferents increases the resting discharges of afferents (Goldberg and Fernández, 1980; Plotnik et al., 2002; Sadeghi et al., 2009a), we speculated that the observed light-induced inhibition could be due to heat-mediated inhibition of efferent fibers. In support of this idea, a previous study in toadfish has shown that heat does not have a retrograde effect on afferent nerve axons (Rajguru et al., 2011). As expected from a heat-mediated effect, once the OF was placed in between positions $\mathrm{G}$ and $\mathrm{A}(n=2)$, where the temperature would increase over the fibers as well as the gan- glion, the two effects cancelled each other, and little or no change was observed in afferent firing rates (Fig. 1D).

For the population of recorded afferents with the fiberoptic in position $\mathrm{A}$, there was a direct relationship between irregularity of resting discharge (quantified by $\mathrm{CV}^{*}$ ) and the magnitude of the inhibitory effect (Fig. 2A1,B1). This is similar to the trend observed for excitatory responses of afferents to efferent electrical stimulation (e.g., Marlinski et al., 2004, their Fig. 10). The relation between the magnitude of inhibition and $\mathrm{CV}^{\star}$ was present, even for smaller temperature changes $\left(\sim 5.7^{\circ} \mathrm{C}\right)$ with $3 \mathrm{~s}$ stimulation. The proportion of irregular afferents that were shut down during stimulation increased from $38 \%$ with $3 \mathrm{~s}$ stimulation to $65 \%$ with $10 \mathrm{~s}$ stimulation (Fig. $2 A 2, B 2$ ), whereas that of regular afferents only showed a slight increase from $21 \%$ to $29 \%$. The percentage inhibition of resting discharge (Fig. 2C) for irregular afferents increased from $77.39 \pm 6.5 \%$ with $3 \mathrm{~s}$ stimulation to $91.86 \pm 6.5 \%$ with $10 \mathrm{~s}$ stimulation $(n=13$, paired $t$ test, $p=$ $0.02)$. For regular afferents, resting discharge inhibition increased from $34.62 \pm 6.62 \%$ for 3 s to $54.56 \pm 8.16 \%$ for $10 \mathrm{~s}$ stimulation $(n=32$, paired $t$ test, $p=0.0002)$.

With the $\mathrm{OF}$ in position $\mathrm{G}$ (i.e., over the ganglion), the majority of fibers $(65 \%)$ showed an increase in the resting discharge consistent with previous studies demonstrating excitation with increasing temperature over the ganglion region (Dittami et al., 2011). While most regular and irregular afferents showed excitatory responses, a higher percentage of irregular afferents (compared with regular afferents) were still inhibited (Fig. 2D). In a small fraction of afferents, an inhibitory response followed by excitation was observed during stimulation. This variability could be due to the combination of excitation of afferent cell bodies and inhibition of efferent fibers that pass through the ganglion, similar to when the OF was between positions A and G (Fig. 1D) and as further addressed in the Discussion.

\section{Optothermal inhibition of afferents is mediated by efferents} To specifically target the efferent fibers, we positioned the OF over brainstem midline to selectively affect commissural efferent 
A

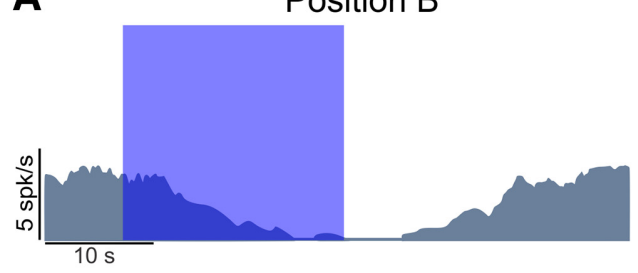

B

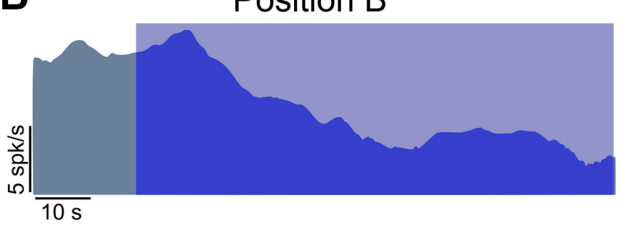

C

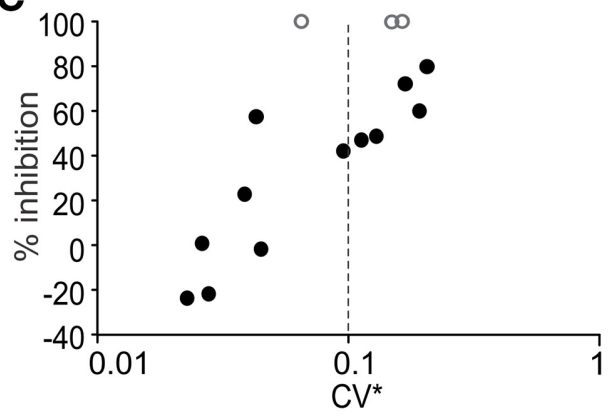

E1 $100 \%$ blue, position B only
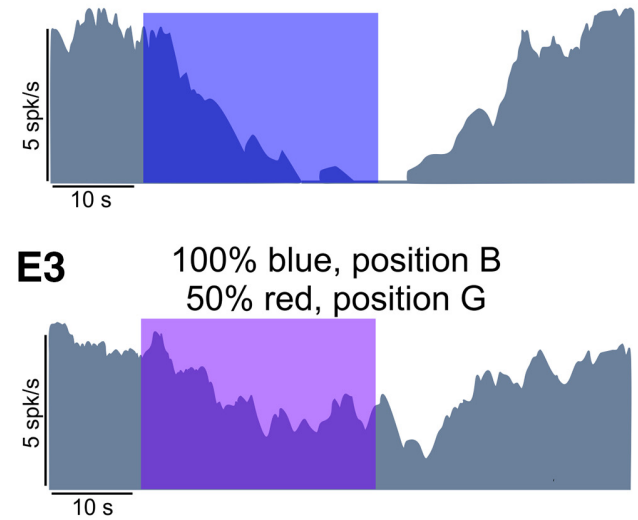

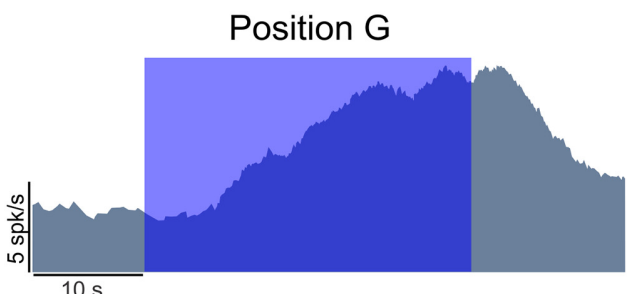

$0.5 \mathrm{~mm}$ posterior to Position $\mathrm{B}$

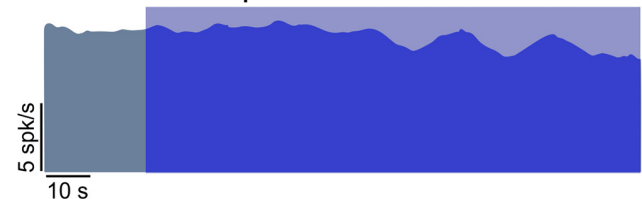

Position A - control

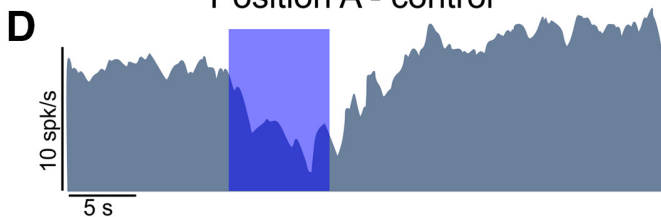

Position A - nerve cut

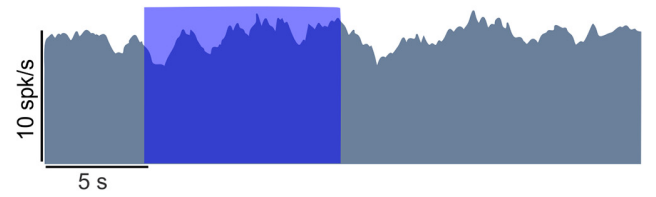

E2

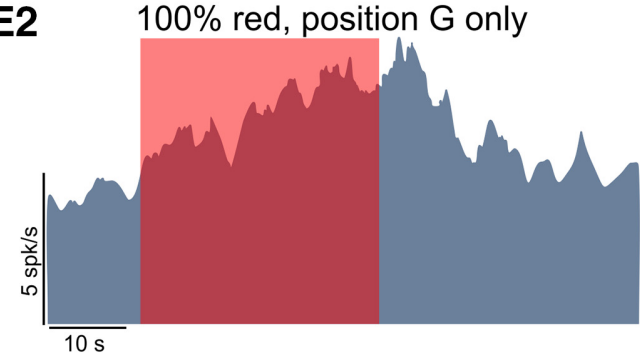

E4

$50 \%$ blue, position B $100 \%$ red, position $\mathrm{G}$

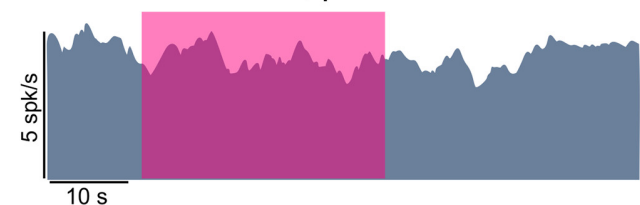

Figure 3. Afferents were inhibited by heating efferent fibers crossing the brainstem midline. $A$, An afferent that showed excitatory response to stimulation at position $G$ could be inhibited when the fiber was moved over the brainstem (position B), a position used by others (Goldberg and Fernández, 1980; Marlinski et al., 2004) for electrical stimulation of crossing efferent fibers, suggesting an efferent origin for the inhibitory effect. $\boldsymbol{B}$, The response in position $B$ was highly dependent on location and had spatial specificity, and movement away from this position by $0.5 \mathrm{~mm}$ resulted in the loss of inhibition. C, The amount of inhibition was proportional to the irregularity of afferent discharges, further confirming their efferent origins. A CV* of 0.1 (dashed line) was used to divide the afferents into regular and irregular groups. $\boldsymbol{D}$, In an afferent with inhibitory responses at position A, cutting the nerve (i.e., efferent fibers) resulted in the loss of inhibition. $\boldsymbol{E}$, Effect of simultaneous stimulation at positions $G$ (with red LED) and B (with blue LED) with two OFs. The example afferent showed an inhibitory response to stimulation at position B with maximum light power (E1) and excitatory response at position $G$ with maximum light power (E2). The red LED had lower maximum power (see Materials and Methods). Combination of the two stimuli with different maximum powers showed a combination of inhibitory (efferent-mediated) and excitatory (afferent-mediated) responses (E3, E4).

fibers as shown in other mammals: squirrel monkey (Goldberg and Fernández, 1980), cat (Warr, 1975), gerbil (Perachio and Kevetter, 1989), and rat (Wang et al., 2013). This is the same position used for electrical stimulation of vestibular efferents at the floor of the fourth ventricle (Marlinski et al., 2004). The OF was advanced ventrally at the midline of the cerebellum until an effect was observed. Typically, responses were detected at a depth of $\sim 4 \mathrm{~mm}$ from the surface, which matched our anatomical measurements in killed animals and values obtained from a mouse brain atlas (Paxinos and Franklin, 2004).

Figure $3 A$ shows a representative irregular afferent that was inhibited by optothermal stimulation over the brainstem midline (position B). The same fiber showed an increase in resting discharge with the $\mathrm{OF}$ at position $\mathrm{G}$. A change in position of the $\mathrm{OF}$ 
resulted in loss of inhibition (Fig. 3B), suggesting that the affected area was highly localized. In our sample of recordings $(n=15)$, the amount of inhibition was directly related to the irregularity of the afferent resting discharge (Fig. $3 C$ ), similar to that observed at position A (Fig. 2A1,B1). Inhibition of afferents with the $\mathrm{OF}$ at position B strongly implicates the involvement of the efferent vestibular pathway.

To further confirm that the inhibitory effects at positions A and B were mediated solely through efferents in the nerve bundle, we suctioned part of the nerve between the ganglion and brainstem, thereby disconnecting the efferent fibers from the targets in the vestibular epithelium. To avoid any heat dissipation between areas, a biocompatible cast (Kwik-Cast, WPI) was applied in the craniotomy once the $\mathrm{OF}$ and the electrode where in position. The cast did not have any effect per se on the inhibition observed in irregular afferent fibers before cutting the nerve (data not shown). After cutting the nerve, no inhibition was observed (Fig. $3 D)$ in any of the recorded fibers $(n=7$, control resting rate $=$ $14.96 \pm 2.83$ spikes/s, resting rate with light stimulation $=$ $16.06 \pm 2.84$ spikes/s, paired $t$ test, $p=0.12$ ). These results further confirm the involvement of efferent vestibular pathway in the observed inhibition of irregular afferent fibers.

We explored the interaction between the excitatory effect of heat on vestibular ganglion cell bodies and the inhibitory effect on efferent fibers by using two OFs: one at position $G$ and one at position B (Fig. 3E). The OF positioned over the ganglion was connected to a red LED $(655 \mathrm{~nm})$ and the one at the brainstem to a blue LED. Turning on the blue LED in position B (efferent fibers) inhibited the resting discharge of afferent fibers by $100 \%$ (Fig. 3E1), whereas turning on the red LED in position G (vestibular ganglion) resulted in an increase in resting discharge by $76 \%$ (Fig. 3E2). When both LEDs were turned on simultaneously, their individual effects counteracted each other. With blue light at full power and red at half power, the sum of the two resulted in $50 \%$ inhibition (Fig. 3E3), suggesting that the stimulation of the ganglion when the afferents were shut down produced only $50 \%$ of the resting discharge. Assuming that the effects would interact linearly, with the blue light at half power and red at full power an inhibition of $12 \%$ (i.e., $\mathrm{rr}-(0.5 \mathrm{rr})(1.76)=0.12 \mathrm{rr}$, where $\mathrm{rr}$ is resting rate) was expected. The observed inhibition was $18 \%$ (Fig. $3 E 4)$, suggesting a near linear and independent interaction. These results were similar to that observed with the fiberoptic in between positions A and G (Fig. 1D). The relation between LED power and amount of inhibition is further addressed below. Together, these results provide strong evidence for efferentmediated differential inhibition of afferents by heat.

\section{Effect of stimulation parameters on inhibitory responses}

The absence of sensitivity to light (rather than heat) is supported by the fact that, while light-sensitive responses in photoreceptors and optogenetic studies have short latencies of a few milliseconds, response latencies in our study were in the order of a few seconds at stimulus onset and offset, comparable with the time scale of the change in temperature (Fig. 1B). To further elucidate the effect of heat on inhibition, different intensities or durations of light were used to produce a spectrum of temperatures at position A. First, we observed that, for fixed durations, the inhibition increased as a function of intensity of the light (Fig. 4A1). In the same afferent, for fixed intensities, inhibition increased with increasing durations of stimulation (Fig. 4B1). For the population of recorded fibers under different conditions $(n=6)$, average inhibition increased with increasing intensity or duration of light application (Fig. 4A2,B2). Furthermore, a direct relation was observed be- tween the maximum inhibition and peak temperatures attained during various protocols (Fig. $4 C$ ), which were directly related to the intensity and duration of the stimulation (Fig. 4D).

Another important difference between heat- and lightmediated effects is that the latter has spectral sensitivity. To test for wavelength-dependent effects, we used interchangeable blue and red LEDs connected to an OF at position A. Regardless of the color of the light, the afferent resting discharge was inhibited (Fig. $5 A$ ). The inhibition was stronger with the blue LED compared with the red LED for all recorded cells (Fig. $5 B$ ), which could be explained by the lower temperature changes elicited by the red LED (Fig. 5C).

From the above results, it follows that the intensity of inhibition should, to a first-order approximation, scale with the size of the stimulated area (i.e., higher total energy). To test this, we positioned two OFs, side by side over the distal part of the nerve. Although individual fibers showed a bias in their responses toward one or the other OF (Fig. 5D), the population of recorded afferents did not follow a trend in this regard (Fig. 5E). The inhibition was higher when a larger area of the nerve was heated by 2 OFs than the response to individual OFs (Fig. $5 F$ ). Interestingly, the inhibition observed with simultaneous stimulation by both LEDs $(77.4 \pm 6.29 \%)$ was statistically less than that observed by summation of the inhibition of individual LEDs (83.46 $\pm 5.42 \%$, paired $t$ test, $p=0.005)$. This sublinear summation is most likely due to the strong afferent inhibition by each LED and the nonlinearities near zero firing rate. Together, these results show that the inhibitory response depends on the duration, intensity, and stimulated surface area, parameters that affect the amount of absorbed energy and the resultant temperature rise.

\section{Thermal stimulation by using warm saline}

As an alternate to OFs, we manually applied 2-3 drops of warm $\left(\sim 40^{\circ} \mathrm{C}\right)$ sterile saline directly over the visible nerve while recording from an afferent fiber that could be inhibited by OF (Fig. $6 A 1)$. The temperature measured near the nerve fiber quickly changed from room temperature $\left(\sim 23^{\circ} \mathrm{C}\right.$ ) to $\sim 35^{\circ} \mathrm{C}$ (Fig. $6 \mathrm{~A} 2$, inset), which resulted in an inhibition of the afferent fiber. Interestingly, application of cold saline $\left(\sim 4^{\circ} \mathrm{C}\right)$ resulted in a visible excitation of the cell (Fig. 6A3). This increase in firing rate could simply be attributed to the opposite effect of heat on efferents (i.e., disinhibition) and is further addressed in the next section. It is possible that such effects also contribute to the reported improvement of symptoms with cooling in patients with demyelination disorders, such as multiple sclerosis (Regan et al., 1977; Feys et al., 2005; Frohman et al., 2011).

While this mode of application certainly showed the effect of temperature change, dissipation of heat was rapid and lasted only for $\sim 1 \mathrm{~s}$. To overcome this problem, we used continuous application of saline with a pump and a temperature controller unit, which allowed the temperature to rise and stay at a higher temperature (Fig. 6B, top). This stimulation resulted in an inhibitory response in most afferent fibers (Fig. 6B, bottom). Notably, compared with OF stimulation, a lower rise in temperature with saline could result in much higher inhibitions, presumably because temperature changed over a larger surface area of the nerve (i.e., the length of the exposed nerve in the craniotomy), in accordance with the results observed in Figure 5D. For the population of recorded fibers during saline application, most of the afferents showed an inhibitory response to heat and included both regular and irregular afferents, with mean $\mathrm{CV}^{\star}$ of $0.1 \pm 0.01$ (Fig. $6 C$ ). Many of these afferents shut down for the smallest possible stimulation. Interestingly, stabilized temperature plateaus showed a 
A1

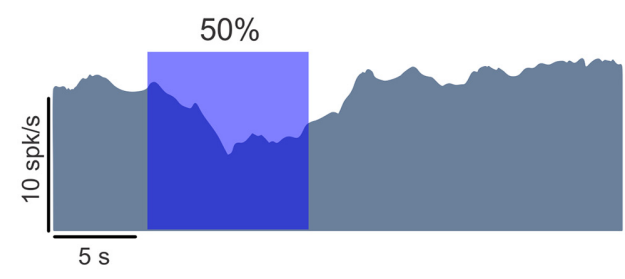

B1

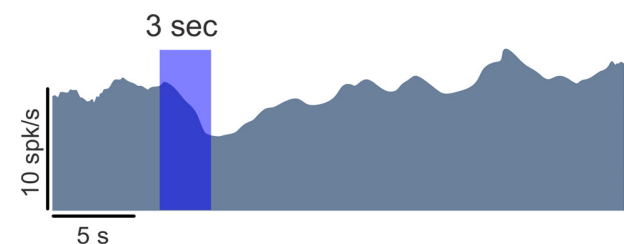

C

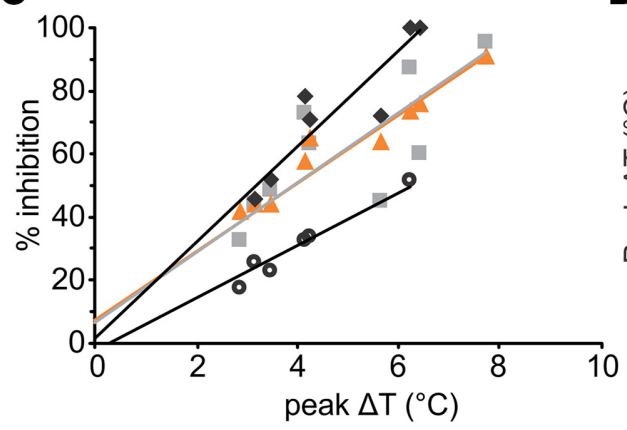

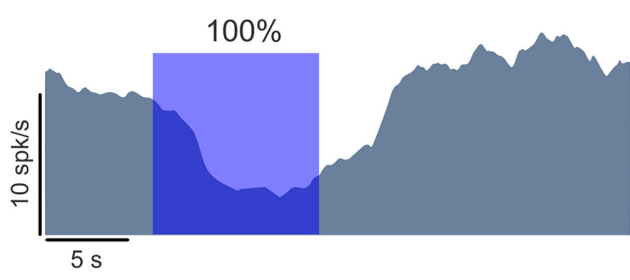

A2

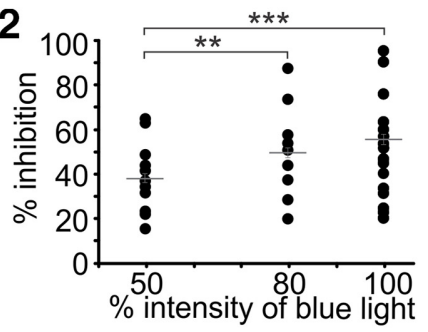

B2

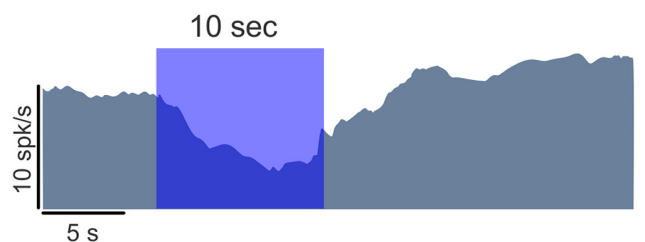

D

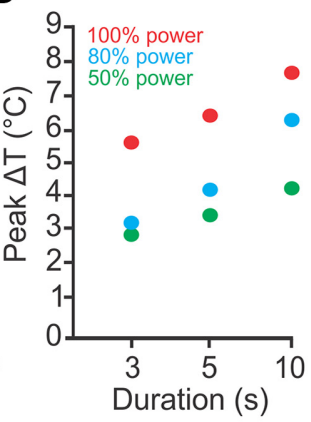

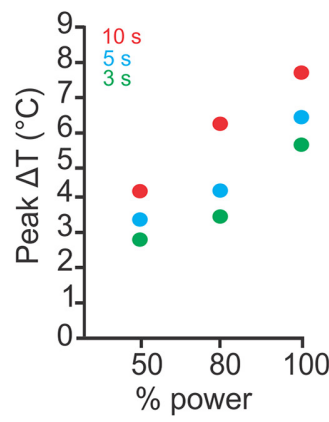

Figure 4. Inhibition intensity was directly related to the light intensity and duration. $\boldsymbol{A}$, Increase in inhibition of an irregular afferent (CV* $=0.102)$ with an increase in the LED power for a $10 \mathrm{~s}$ stimulus (A1). For the population of afferents (A2), light intensities of 30\%, 50\%, and 100\% resulted in $55.5 \pm 6.27 \%$, $49.7 \pm 5.45 \%$, and 38.02 $\pm 4.05 \%$ inhibition, respectively (repeatedmeasures ANOVA, $p<0.0001$, Tukey's post hoc test). ${ }^{* *} p<0.001 .{ }^{* * *} p<0.0001$. $\boldsymbol{B}$, Inhibitory effect increased with an increase in the duration of stimulation at maximum light intensity as shown for an example afferent (B1) and for the population of afferents recorded (B2). Stimulus durations of 3, 5 , and 10 s resulted in $61.8 \pm 6.32 \%, 44.59 \pm 5.29 \%$, and $36.84 \pm 4.21 \%$ inhibition, respectively (ANOVA, $p=0.0074$, Tukey's post hoc test). ${ }^{* * *} p<0.0001$. C, Percentage inhibition was directly related to the maximum change in temperature. Four afferents with at least 6 instances of heating are shown. The 4 linear fits to the data had $R^{2}>0.6$. Fit equations: circles represent $14.28 x+5.39$; squares represent $9.25 x+15.35$; diamonds represent $9.56 x-8.21$; triangles represent $9.56 x+14.36$. D, Temperature increased in proportion to the increase in duration with fixed intensity (left) or increase in intensity with fixed duration (right).

revival of the inhibited afferents, which will be further addressed in the next section.

All afferents that showed excitation in direct relation to the change in temperature (Fig. $6 D, E$ ) were regular afferents with very low $\mathrm{CV}^{\star}$ values $\left(\mathrm{CV}^{\star}=0.04 \pm 0.005\right)$ (Fig. $6 \mathrm{C}$ ). In addition to a direct effect of heat on afferent cells bodies in the ganglion, this excitation could be due to inhibition of inhibitory efferent inputs onto Type II hair cells that provide inputs to regular fibers (Kong et al., 1997; Jordan et al., 2015; Poppi et al., 2018). Finally, a few fibers $\left(\mathrm{CV}^{*}=0.09 \pm 0.026\right)$ showed no response to temperature rises, possibly due to the inhibition and excitation negating each other. The salient feature of these experiments is that the direction of change in afferent resting discharge depends on the interplay between the dynamics of inhibition of efferents as well as the direct excitatory effect of heat on ganglion cells, as previously demonstrated using OF (Fig. 3E). Thus, the resultant excitation or inhibition in resting discharge of an afferent fiber provides an insight into the importance of efferent inputs for its normal function.

\section{Differential effect of temperature and rate of change of temperature}

As mentioned above, inhibition of afferents was mainly observed during the period of temperature change; and once a steady temperature was reached, resting discharges revived, suggesting a more prominent role for change in temperature rather than the final temperature itself. To identify the most important thermal parameters, we used heating profiles with different rates of temperature change and different steady-state temperatures. By using a combination of different rates of application of saline by the pump and different maximum set temperatures of the heater, three modes of heating profiles were achieved (Fig. 7A, top). Each profile was characterized by a distinct rate of rise and relatively stable plateau that lasted $>100 \mathrm{~s}$, followed by a slow uncontrolled cooling back to room temperature. During the temperature steady state, the firing rate of cells that were initially inhibited increased exponentially over time (Fig. $7 B$ ) to near baseline values, suggesting a recovery of efferent activity. We verified this in two recordings by showing that optothermal stimulation at position A resulted in inhibition during such temperature plateaus. In $\sim 50 \%$ of afferents, the resting rates were greater at high temperatures compared with room temperature.

Most afferents shut down in response to the lowest heating profile. In a subpopulation of afferents that did not shut down and could be held during multiple profiles, a direct relation was observed between peak change in firing rate and the corresponding stimulation profile (both heating and cooling) (Fig. 7C). Afferent resting discharges decreased during the temperature rise from room temperature $\left(\sim 26^{\circ} \mathrm{C}\right)$ to $29^{\circ} \mathrm{C}, 32^{\circ} \mathrm{C}$, or $35^{\circ} \mathrm{C}$. As the nerve cooled back to room temperature, the afferents showed an 
A
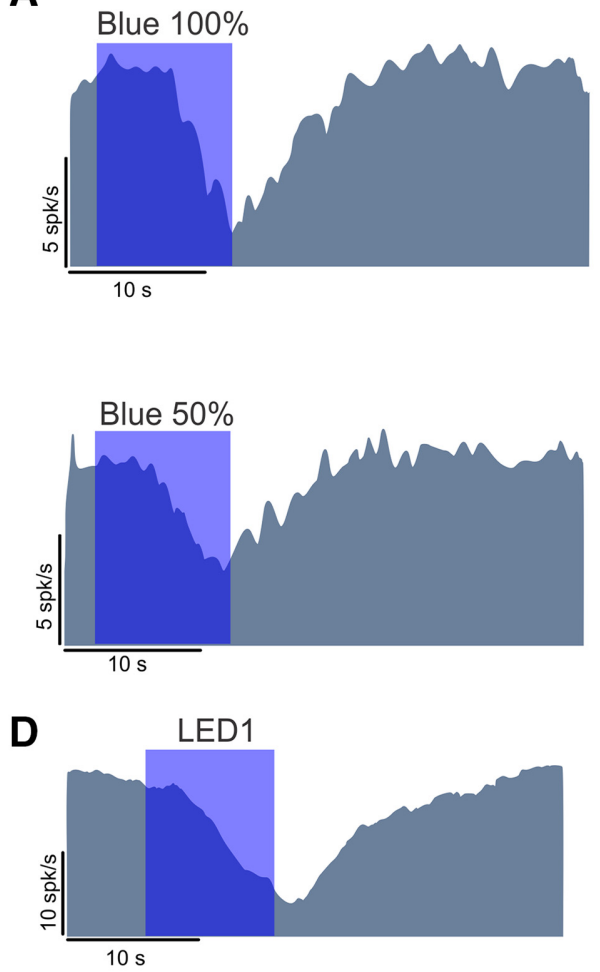

E

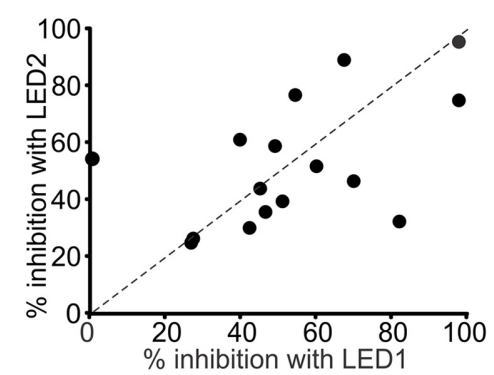

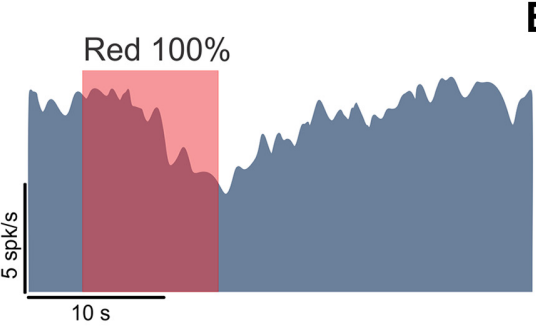

B

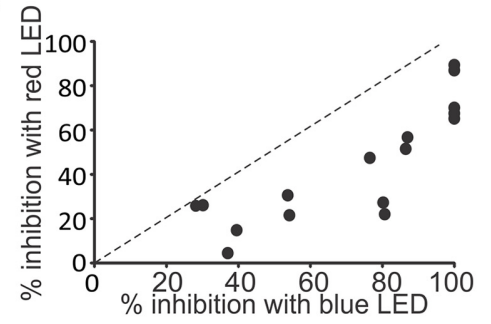

c
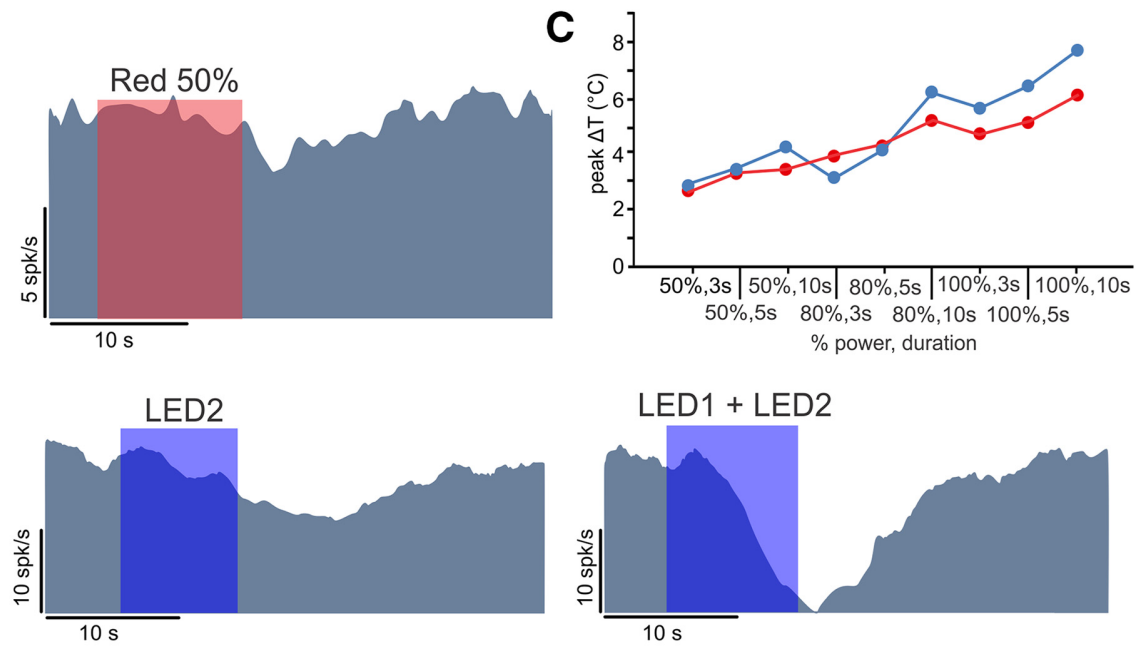

$\mathbf{F}$
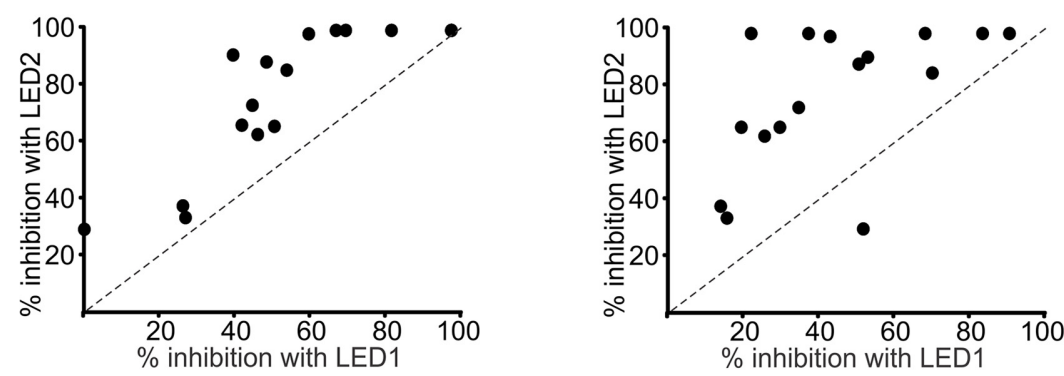

Figure 5. Heat-mediated inhibitory effect was not dependent on the wavelength of the light but was affected by the size of the stimulated area. $\boldsymbol{A}$, An example irregular afferent inhibited by blue $(460 \mathrm{~nm})$ or red $(655 \mathrm{~nm})$ LEDs of different intensities (10 s duration) at position A. B, Blue and red light both resulted in inhibition in 16 afferents (CV* range $0.023-0.25$ ). The effect of red light was less (i.e., all points lie under the $y$ - $x$ dashed line) due to the lower power of the red LED. C, Different intensities and durations of stimulation with red light resulted in smaller temperature changes compared with blue light (data from Fig. 4). D, A representative irregular afferent that was inhibited by each of the two OFs positioned over the nerve near the brainstem. Inhibition increased with simultaneous stimulation by the two OFs (i.e., increased size of the stimulation area). $\boldsymbol{E}$, Population of 14 afferents recorded with two LEDs showed a range of inhibitions with no bias toward either LED. $\boldsymbol{F}$, The inhibition observed by two LEDs was higher than that observed for each LED individually (i.e., points lie above the $y$ - $x$ dashed line).

initial excitation in response to the sharp fall in temperature and a slow subsequent reduction in firing rate. The similarity of the inhibition and excitation effects (Fig. 7C) suggests that the same process underlies both responses. A simple explanation for these effects is that efferents are inhibited by the rise in temperature; and once the temperature drops, it results in a release from this inhibition or even excitation, which would increase the resting discharge of the same afferents.

Given that firing rates started to rise once the temperatures plateaued, instantaneous temperature could not be the only factor governing the inhibition. Moreover, the peak inhibition of firing rate $($ Fig. $7 A, t 2)$ preceded the peak change in temperature (Fig. $7 A, t 3$ ), suggesting that the rate of change of temperature (dT/dt, peaked at $t 1$ ) could be a contributing factor to the observed inhibition. Using linear polynomial fits (Eq. 1), we found that the responses were best described by fits using both change in temperature $(\Delta \mathrm{T})$ and $\mathrm{dT} / \mathrm{dt}\left(R^{2}=0.81\right)$ compared with using only $\Delta \mathrm{T}\left(R^{2}=0.65\right)$ or $\mathrm{dT} / \mathrm{dt}\left(R^{2}=0.04\right)($ Fig. $7 D)$. Also, the lag of peak inhibition with respect to peak $\mathrm{dT} / \mathrm{dt}$ decreased with an increase in $\mathrm{dT} / \mathrm{dt}$, supporting a causal relation between the two (Fig. 7E). The best fit provided gains for $\Delta \mathrm{T}$ and $\mathrm{dT} / \mathrm{dt}$ (represented by $a$ and $b$ in the equation). While gains with respect to $\Delta T$ were nonlinear and became more positive from low through high heating profiles (Fig. $7 F$ ), those with respect to $\mathrm{dT} / \mathrm{dt}$ were linear and remained unchanged (Fig. $7 G$ ). These findings strongly suggest that the rate of temperature change, as well as the net temperature change, contribute to the firing rate inhibition.

Similarly, in another group of afferents that showed excitatory responses in direct relation to rises in temperature (Fig. $7 H$ ), a combination of $\Delta \mathrm{T}$ and $\mathrm{dT} / \mathrm{dt}$ provided the best fit (Fig. 7I). Again, gains with respect to $\Delta \mathrm{T}$ increased from low through high temperature profiles, whereas $\mathrm{dT} / \mathrm{dt}$ gains remained constant (Fig. $7 \mathrm{~J}, \mathrm{~K}$ ). The smaller values of the $\mathrm{dT} / \mathrm{dt}$ gains and positive $\Delta \mathrm{T}$ gains for excitatory responses, as opposed to larger $\mathrm{dT} / \mathrm{dt}$ gains and negative $\Delta \mathrm{T}$ gains observed for afferents with inhibitory responses, suggest lower dependence of the former on efferent in- 
A1

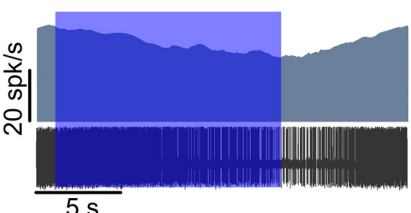

B
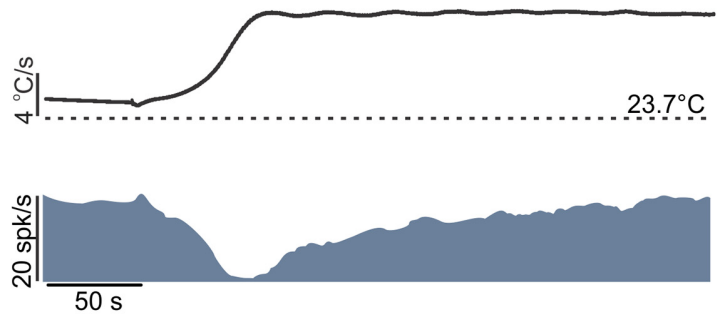

D
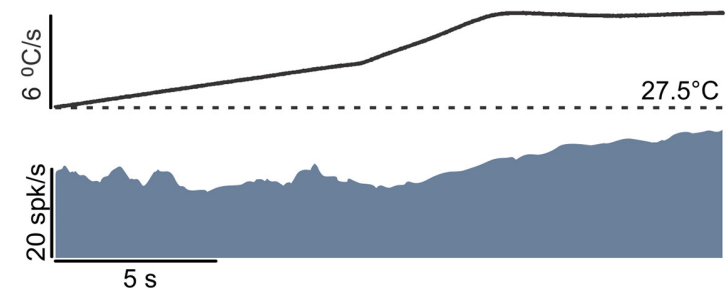

A2

$5 \mathrm{~s}$

$23.7^{\circ} \mathrm{C}$

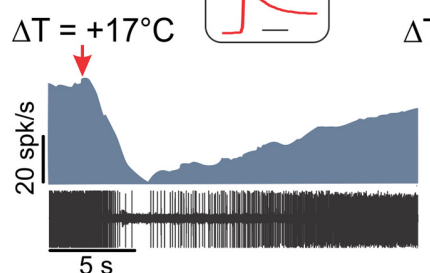

E

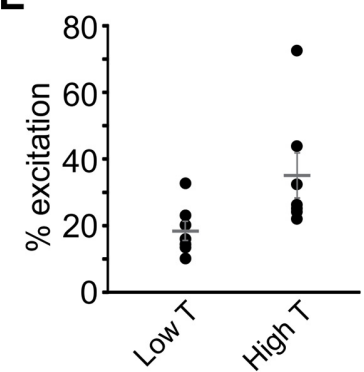

Figure 6. Responses to thermal stimulation by application of saline were comparable with optothermal stimulation. $\boldsymbol{A}$, In an afferent that was inhibited by optothermal stimulation at position A (A1), application of warm saline also inhibited the resting discharge (A2). Application of cold saline had the opposite effect and resulted in an increase in resting discharge of this afferent (A3). Insets, Temperature change. Calibration: $1 \mathrm{~s}$. $\boldsymbol{B}$, Example of inhibition in an afferent using a precision-controlled increase in temperature to a plateau. The firing rate recovered to the resting discharge during the temperature plateau. $C$, For the population of recorded afferents, both regular and irregular afferents could be inhibited, whereas excitatory effects were observed in afferents with regular resting discharge (i.e., $\mathrm{C} \mathrm{V}^{*}<0.1$ ). Some afferents did not show any response to warm saline, presumably due to the cancellation of the excitatory effect (on ganglion cells) and inhibitory effect (on efferents). $\boldsymbol{D}$, Example of increase in resting discharge of a regular afferent $\left(\mathrm{C}^{*}=0.026\right)$ with increase in temperature. $\boldsymbol{E}$, For the population of afferents with excitatory responses, the increase in firing rate was in direct relation to the rise in temperature $(n=6$, paired $t$ test, $p=0.016)$. The high and low temperatures were in the range of $23^{\circ} \mathrm{C}-24^{\circ} \mathrm{C}$ and $33^{\circ} \mathrm{C}-37^{\circ} \mathrm{C}$, respectively.

puts. These results combined with results in Figure $6 C$ suggest that only regular afferent resting discharges could be independent of efferent activity.

Together, the above results provide strong evidence that a positive rate of temperature change is mandatory for inhibition of efferents, resulting in inhibition of afferents and that direct excitation of ganglion cells is immune to efferent-mediated inhibition only in regular fibers.

\section{Discussion}

In this study, we provide evidence that the efferent vestibular pathway that innervates the vestibular end organs plays a critical role in modulating firing patterns of vestibular afferent nerve fibers. We show that inhibition of efferents results in a decrease in, or complete inhibition of, the spontaneous discharge of afferents. Consistent with previous studies, the strength of the efferent-mediated inhibition was directly related to the irregularity of the resting discharge. This suggests that, without active efferent inputs, irregular afferents may have zero resting discharges, resulting in decreased overall sensitivity due to the afferents functioning at the lower ends of their input-output curves. Furthermore, with no resting discharge, responses of irregular afferents become asymmetric during head movements in the two directions due to elimination of their ability to encode fast head movements of inhibitory polarities. This would be particularly problematic because irregular afferents are optimal at encoding high-frequency movements (Goldberg et al., 1990b; Lysakowski et al., 1995; Ramachandran and Lisberger, 2006; Sadeghi et al., 2007a,b; Eatock and Songer, 2011).

Although it is not possible to directly record from efferent fibers due to their scarcity and the difficulty of recording from thin fibers, several lines of evidence from our results suggest that a rise in temperature inhibits the firing of vestibular efferent fibers, which are unmyelinated or lightly myelinated. First, heat does not excite the efferents because we know from previous studies that efferent stimulation increases the resting discharge of afferents in mammals. Second, the temperature-induced inhibition of afferent resting discharges was directly related to the irregularity of their resting discharges, in accordance with previous efferent stimulation studies (Goldberg and Fernández, 1980; Marlinski et al., 2004; Sadeghi et al., 2009a). Third, afferent inhibition was also achieved by positioning the fiberoptic over the brainstem midline. Fourth, the inhibitory effect was annulled by cutting the nerve, effectively disconnecting the efferents from the end organs. Finally, direct inhibition of afferent fibers could not be considered because (1) an excitatory effect was observed with the OF positioned close to the ganglion (Fig. 1D), (2) application 

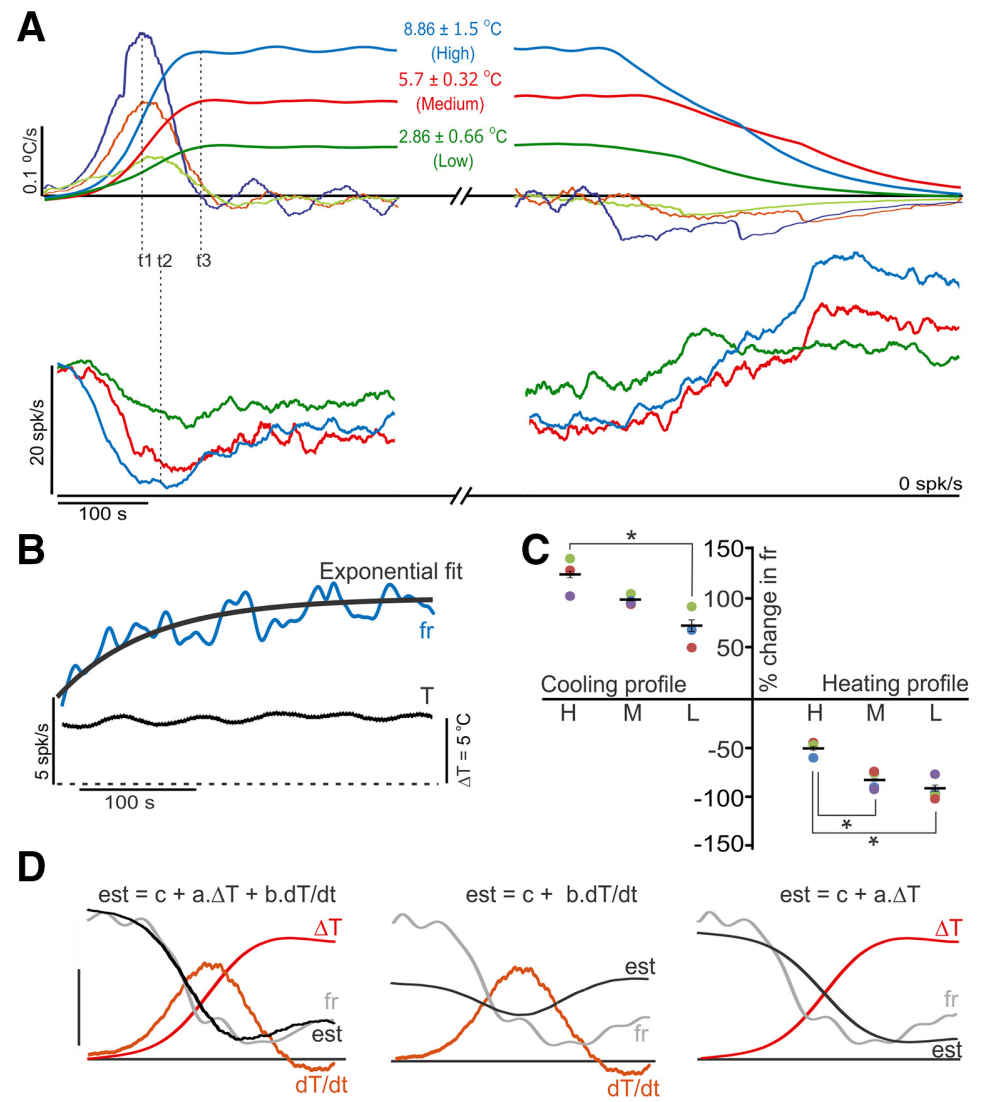

E
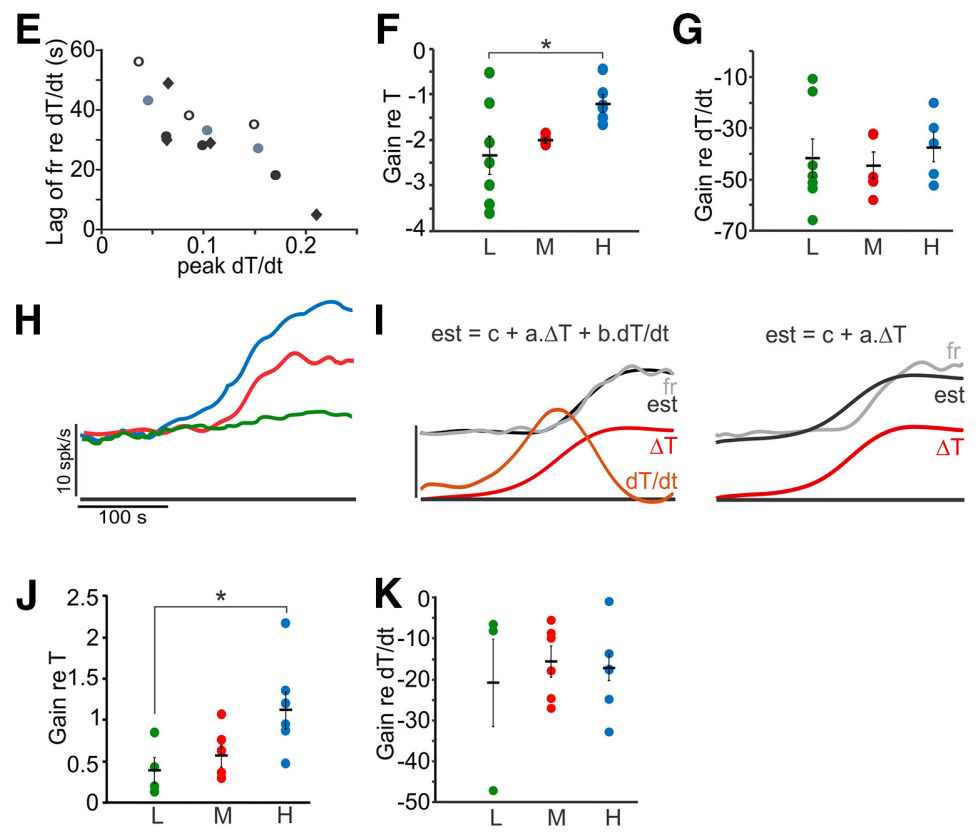

Figure 7. Temperature change and its rate contribute to the observed effects on afferent resting discharges. $\boldsymbol{A}$, Temperature profiles and changes in firing rate of a representative irregular afferent. Top traces represent temperature change $(\Delta T)$ and its rate of change (dT/dt). Bottom traces represent corresponding firing rates, color coded for each profile. Horizontal black line indicates zero for all traces. Dashed lines at $t 1, t 2$, and $t 3$ indicate peak $\mathrm{dT} / \mathrm{dt}$, firing rate inhibition, and $\Delta \mathrm{T}$, respectively. $\boldsymbol{B}$, During plateau temperature, firing rate exponentially recovered to near baseline values. Final stable firing rate was estimated from the exponential fit at $t_{\text {infinity. }}$. Dashed horizontal line indicates zero for both traces. $\boldsymbol{C}, \ln 4$ afferents (different colors) recorded during at least 5 of the different heating profiles and subsequent uncontrolled cooling, a direct relation was observed between peak change in firing rate and the corresponding stimulation profile (one-way ANOVA and Tukey's post hoc test, ${ }^{*} p<0.001$ ). D, A linear polynomial fit was used to estimate the firing rate. Using both $\Delta \mathrm{T}$ and $\mathrm{dT} / \mathrm{dt}$ provided the best fit compared with using only $\mathrm{dT} / \mathrm{dt}$ or only $\Delta \mathrm{T}$. Horizontal black line indicates zero for all traces. Calibration: 10 spikes $/ \mathrm{s}, 3.13^{\circ} \mathrm{C}, 0.09^{\circ} \mathrm{C} / \mathrm{s}$. $E$, Response lags (with respect to dT/dt) decreased with increasing dT/dt. Calibration: 12 spikes $/ \mathrm{s}, 4^{\circ} \mathrm{C}, 0.1^{\circ} \mathrm{C} / \mathrm{s}$. $\boldsymbol{F}$, Estimated gain for $\Delta \mathrm{T}$ increased as a function of $\Delta \mathrm{T}$ (ANOVA, $p=0.0058$, Tukey's post hoc test only significant for $L$ vs $H, p<0.01$ ), suggesting a nonlinear effect of $\Delta T$ on firing rate. $\boldsymbol{G}$, Estimated gain for $\mathrm{dT} / \mathrm{dt}$ showed a linear effect of $\mathrm{dT} / \mathrm{dt}$ on firing rate (ANOVA, $p=0.81$ ). $\boldsymbol{H}$, Increase in resting discharge of an of heat at the midline brainstem should not affect the upstream afferents, and (3) cutting the nerve should not affect a direct afferent inhibition. On the other hand, inhibition of efferents is sufficient to explain all of our findings.

Previous studies have shown heatbased inhibitions in unmyelinated/thinly myelinated fibers (Wang et al., 1999; Chow et al., 2009; Rojas and GonzalezLima, 2011; Yan et al., 2011; Duke et al., 2013; Kingsley et al., 2014; Lothet et al., 2014, 2017). Moreover, increase in body temperature in patients with demyelination disorders results in inhibition of these fibers and exacerbation of symptoms (Wang et al., 1999; Frohman et al., 2011). Although the mechanism underlying this inhibition is not understood (Cayce et al., 2011), a decrease in mitochondrial ATP and disruption of fast axonal flow in unmyelinated fibers (Chow et al., 2007) and a decrease in sodium channel open times (Schwarz and Eikhof, 1987; Straver et al., 2011) have been proposed as possible candidates. On the other hand, heating typically results in excitation/depolarization of myelinated neurons (Izzo et al., 2006, 2008; Richter et al., 2008; Littlefield et al., 2010; Rajguru et al., 2011), consistent with afferent excitation when the OF was at position $\mathrm{G}$.

Understanding the underlying mechanisms for efferent-mediated afferent responses has proven to be challenging due to the complexity of efferent innervation of the different types of afferents. Afferents with the highest $\mathrm{CV}^{\star}$ values (irregularity) have only calyx terminals (Fig. 8, \#1) (Goldberg et al., 1992) and show robust excitation to efferent stimulation, an effect mediated through $\alpha 4 \beta 2$ or $\alpha 6 \beta 2$ nicotinic receptors (Holt et al., 2015) and muscarinic receptors (mAChR), which inhibit KCNQ potassium channels (Pérez et al., 2009; Kalluri et al., 2010; Holt et al., 2017; Lee et al., 2017). Inhibition of efferents should therefore have the opposite effect and decrease the spontaneous firing in these afferents, as observed in the present study. On the other hand, afferents with the lowest $\mathrm{CV}^{\star}$ values innervate only Type II hair cells (Fig. 8, \#4) (Goldberg et

$\leftarrow$

example regular afferent with different heat profiles. Horizontal black line indicates $0 . I$, Excitation could best be described by using both $\Delta \mathrm{T}$ and $\mathrm{dT} / \mathrm{dt}$. Horizontal black line indicates 0 . Calibration: 10 spikes $/ \mathrm{s}, 6^{\circ} \mathrm{C}, 0.1^{\circ} \mathrm{C} / \mathrm{s}$. J, Estimated gain for $\Delta \mathrm{T}$ increased as a function of $\Delta \mathrm{T}$ (ANOVA, $p=0.03$, Tukey's post hoc test only significant for $H$ vs $L, p<0.05$ ), suggesting a nonlinear effect. $\boldsymbol{K}$, Estimated gain for $\mathrm{dT} / \mathrm{dt}$ showing a linear effect (ANOVA, $p=0.61$ ). 

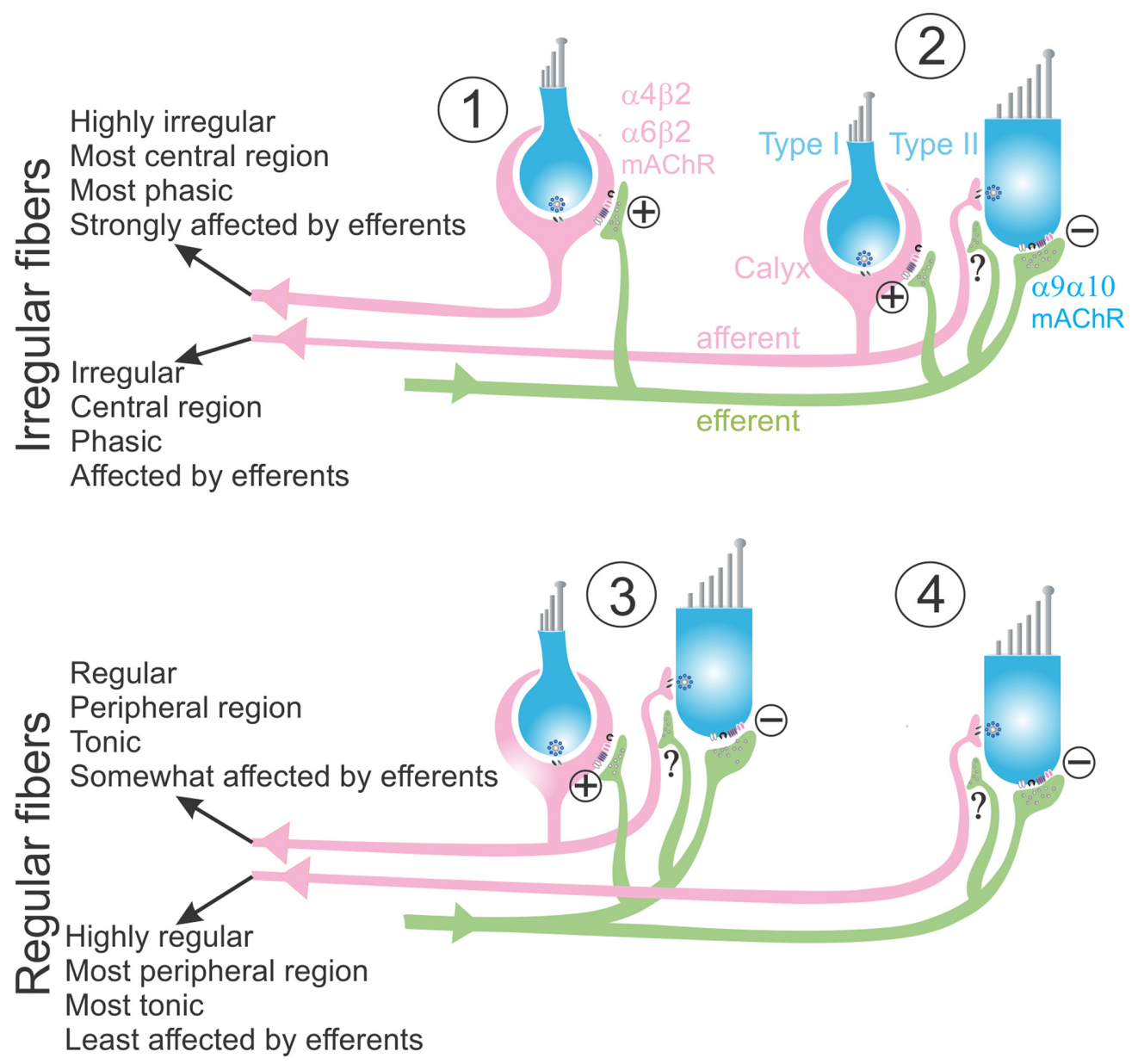

Figure 8. Schematic representing the different types of efferent inputs to regular and irregular afferents. Irregular afferents are presented as either calyx-only (\#1) or dimorphic (\#2) and regular afferents as dimorphic (\#3) or bouton-only (\#4). Efferent inputs to the calyx terminals are excitatory, and those to Typell hair cells are inhibitory. Efferent receptors and their effect on afferent boutons have not been studied directly. In mammals, efferent stimulation results in excitation of all four afferent types.

al., 1992) and show negligible excitation during electrical stimulation of efferents, which is probably due to: (1) hyperpolarization of Type II hair cells through activation of $\alpha 9 / \alpha 10$ and muscarinic receptors, which activate calcium-dependent potassium channels (Kong et al., 2005, 2006; Zhou et al., 2013; Parks et al., 2017; Poppi et al., 2018), resulting in shunting and subsequent decrease in neurotransmitter release; and (2) direct efferent action on bouton terminals, which can be speculated to be excitatory, although not much is known about the exact mechanism. Efferent inhibition protocols used in the present study also show a similar lack of response in highly regular afferents. Finally, most afferents that lie in the middle of the regularity spectrum receive inputs from both Type I and Type II hair cells (dimorphic afferents, Fig. 8, \#2, \#3). Because the net effect of efferents on Type II hair cells/bouton terminals is small, efferent-mediated changes in dimorphic fibers are likely to be dominated by calyx terminals. It has been shown that irregular dimorphic afferents have fewer bouton terminals than regular dimorphic afferents (Goldberg et al., 1990a; Holmes et al., 2017) and are therefore expected to show more robust responses to efferent inputs than regular dimorphic afferents. This is consistent with the inhibition of afferents as a function of $\mathrm{CV}^{\star}$ observed in the present study.

It should be noted that two other properties could further complicate efferent-mediated effects. First, in all vestibular sensory epithelia, the membrane and synaptic properties of hair cells and afferents differ between central regions (innervated mainly by afferents with higher $\mathrm{CV}^{\star}$ ) and peripheral regions (innervated mainly by afferents with lower $\mathrm{CV}^{\star}$ ) (Eatock and Songer, 2011; Lysakowski et al., 2011; Songer and Eatock, 2013; Meredith and Rennie, 2015). Second, in addition to the quantal synaptic transmission, signals between Type I hair cells and their calyx afferent terminals use a nonquantal transmission mediated by accumulation of $\mathrm{K}^{+}, \mathrm{H}^{+}$, and glutamate (Lim et al., 2011; Contini et al., 2012; Songer and Eatock, 2013; Highstein et al., 2014; Sadeghi et al., 2014). This nonquantal transmission may be valuable for fast transmission of signals, which is critical for irregular afferents during fast head movements (Songer and Eatock, 2013). It is possible that efferent-mediated changes (e.g., mAChR modulation of the activity of KCNQ channels on the calyx inner face) (Rocha-Sanchez et al., 2007; Lysakowski et al., 2011) could affect this nonquantal signal transmission.

The effects described above are contingent on efferents having a resting discharge. It has been shown that cochlear efferents have to be stimulated at least at $10 \mathrm{~Hz}$ to facilitate their normally low probability of release (Ballestero et al., 2011), and it is a reasonable assumption that the same is required for vestibular efferents. Vestibular efferents in mouse brainstem slices (Leijon and Magnusson, 2014; Mathews et al., 2015, 2017) have spontaneous resting discharges of up to 5 spikes/s. The main input to efferent neurons is provided by the vestibular nuclei, and the spontaneous activity of vestibular nuclei neurons is $\sim 5$ times higher in alert mice (57.5 $\pm 4.2 \mathrm{spike} / \mathrm{s}$ ) (Beraneck and Cullen, 2007) compared 
with brainstem slices (11 \pm 1 spikes/s) (Sekirnjak and du Lac, 2006). Furthermore, the vestibular nuclei spontaneous rate in anesthetized rats (27.4 \pm 20.9 spikes/s) (Grasso et al., 2016) is $\sim 1.5$ times higher than slices (rat: $18.7 \pm 7.1$ spikes/s) (Saito et al., 2008). As such, efferents are expected to have an average spontaneous discharge rate of close to 10 spikes/s in anesthetized mice and a spontaneous release that could be inhibited by heat. It should also be noted that, despite the low spontaneous rates of efferents, they branch out profusely so that cells and terminals innervated by efferents receive inputs from many terminals (Purcell and Perachio, 1996, 1997). As such, under unstimulated normal conditions, efferent inputs could profoundly influence afferent activity. Consistent with the notion that efferents have a significant functional role, $\alpha 9 \mathrm{KO}$ mice (Eron et al., 2015; Hübner et al., 2015, 2017) and calcitonin gene-related protein KO mice (Luebke et al., 2014) have deficiencies in the vestibulo-ocular reflex response, adaptation, and compensation.

Perfusion of heated saline showed that the aforementioned inhibition is dependent on both temperature and the rate of change of temperature. At steady-state temperatures, the inhibition gradually decreased, resulting in an increase in afferent firing rate. Although LED-based heating shows inhibition to be proportional to the peak temperatures attained, the fact that afferents began to revive once temperatures plateaued during saline application shows that the inhibition of efferents (and consequently afferents) is profoundly dependent on the rate of change in temperature. This is similar to what has previously been shown for heat-mediated excitatory currents that depend on both absolute temperature and its rate of change (e.g., Green and Akirav, 2010; Shapiro et al., 2012; Rabbitt et al., 2016; Luo et al., 2017). To our knowledge, we provide the first line of evidence for thermal inhibition of thin fibers being a rate-dependent process.

Perfusion experiments showed mixed results with both excitation and inhibition of afferents. We suggest that the direction of change in afferent resting discharge depends on the interplay between the dynamics of inhibition of efferents as well as the direct excitatory effect of heat on ganglion cells. This, however, was different from previous studies, which also reported mixed excitation and inhibition of vestibular nerve afferents by IR stimulation of the crista. In guinea pig and rat (Rabbitt et al., 2016), the excitatory responses were attributed to the effect of heat on afferents and inhibitory responses were due to inhibition of hair cells. In toadfish, excitatory effects were observed in afferents with the lowest CVs and inhibition occurred in those with the highest CVs (Rajguru et al., 2011), which is comparable with the responses we observed with respect to regularity (Figs. 2B1, 6C). In both cases, inhibition of efferents was not considered but could have been a contributing factor to the inhibitory responses observed in the afferents.

In conclusion, our results clearly show that efferents are essential for normal afferent function, particularly the irregular/phasic peripheral pathway. This pathway encodes fast head movements and acts as a high-frequency event detector (Sadeghi et al., 2007b). It also participates in the adaptation of the vestibuloocular reflex (Minor and Lasker, 2009) and vestibular compensation (Sadeghi et al., 2007a). Our findings suggest that efferent inputs can affect the relative contribution of regular and irregular pathways through changes in the activity of irregular fibers, thus playing an important role in normal function of the vestibular system as well as its adaptation and compensation following vestibular dysfunction.

\section{References}

Agrawal Y, Ward BK, Minor LB (2013) Vestibular dysfunction: prevalence, impact and need for targeted treatment. J Vestib Res 23:113-117.

Ballestero J, Zorrilla de San Martín J, Goutman J, Elgoyhen AB, Fuchs PA, Katz E (2011) Short-term synaptic plasticity regulates the level of olivocochlear inhibition to auditory hair cells. J Neurosci 31:14763-14774.

Beraneck M, Cullen KE (2007) Activity of vestibular nuclei neurons during vestibular and optokinetic stimulation in the alert mouse. J Neurophysiol 98:1549-1565.

Beraneck M, Straka H (2011) Vestibular signal processing by separate sets of neuronal filters. J Vestib Res 21:5-19.

Cayce JM, Friedman RM, Jansen ED, Mahavaden-Jansen A, Roe AW (2011) Pulsed infrared light alters neural activity in rat somatosensory cortex in vivo. Neuroimage 57:155-166.

Chow RT, David MA, Armati PJ (2007) 830 nm laser irradiation induces varicosity formation, reduces mitochondrial membrane potential and blocks fast axonal flow in small and medium diameter rat dorsal root ganglion neurons: implications for the analgesic effects of $830 \mathrm{~nm}$ laser. J Peripher Nerv Syst 12:28-39.

Chow RT, Johnson MI, Lopes-Martins RA, Bjordal JM (2009) Efficacy of low-level laser therapy in the management of neck pain: a systematic review and meta-analysis of randomised placebo or active-treatment controlled trials. Lancet 374:1897-1908.

Contini D, Zampini V, Tavazzani E, Magistretti J, Russo G, Prigioni I, Masetto S (2012) Intercellular K(+) accumulation depolarizes type I vestibular hair cells and their associated afferent nerve calyx. Neuroscience 227:232-246.

Cullen KE, Rey CG, Guitton D, Galiana HL (1996) The use of system identification techniques in the analysis of oculomotor burst neuron spike train dynamics. J Comput Neurosci 3:347-368.

Dittami GM, Rajguru SM, Lasher RA, Hitchcock RW, Rabbitt RD (2011) Intracellular calcium transients evoked by pulsed infrared radiation in neonatal cardiomyocytes. J Physiol 589:1295-1306.

Duke AR, Lu H, Jenkins MW, Chiel HJ, Jansen ED (2012) Spatial and temporal variability in response to hybrid electro-optical stimulation. J Neural Eng 9:036003.

Duke AR, Jenkins MW, Lu H, McManus JM, Chiel HJ, Jansen ED (2013) Transient and selective suppression of neural activity with infrared light. Sci Rep 3:2600.

Eatock RA, Songer JE (2011) Vestibular hair cells and afferents: two channels for head motion signals. Annu Rev Neurosci 34:501-534.

Eron JN, Davidovics N, Della Santina CC (2015) Contribution of vestibular efferent system alpha-9 nicotinic receptors to vestibulo-oculomotor interaction and short-term vestibular compensation after unilateral labyrinthectomy in mice. Neurosci Lett 602:156-161.

Fernández C, Lysakowski A, Goldberg JM (1995) Hair-cell counts and afferent innervation patterns in the cristae ampullares of the squirrel monkey with a comparison to the chinchilla. J Neurophysiol 73:1253-1269.

Feys P, Helsen W, Liu X, Mooren D, Albrecht H, Nuttin B, Ketelaer P (2005) Effects of peripheral cooling on intention tremor in multiple sclerosis. J Neurol Neurosurg Psychiatry 76:373-379.

Frohman TC, Davis SL, Frohman EM (2011) Modeling the mechanisms of Uhthoff's phenomenon in MS patients with internuclear ophthalmoparesis. Ann N Y Acad Sci 1233:313-319.

Gacek RR, Lyon M (1974) The localization of vestibular efferent neurons in the kitten with horseradish peroxidase. Acta Otolaryngol 77:92-101.

Glowatzki E, Fuchs PA (2000) Cholinergic synaptic inhibition of inner hair cells in the neonatal mammalian cochlea. Science 288:2366-2368.

Goldberg JM, Fernández C (1980) Efferent vestibular system in the squirrel monkey: anatomical location and influence on afferent activity. J Neurophysiol 43:986-1025.

Goldberg JM, Smith CE, Fernández C (1984) Relation between discharge regularity and responses to externally applied galvanic currents in vestibular nerve afferents of the squirrel monkey. J Neurophysiol 51:12361256.

Goldberg JM, Lysakowski A, Fernández C (1990a) Morphophysiological and ultrastructural studies in the mammalian cristae ampullares. Hear Res 49:89-102.

Goldberg JM, Desmadryl G, Baird RA, Fernández C (1990b) The vestibular nerve of the chinchilla: V. Relation between afferent discharge properties and peripheral innervation patterns in the utricular macula. J Neurophysiol 63:791-804. 
Goldberg JM, Lysakowski A, Fernández C (1992) Structure and function of vestibular nerve fibers in the chinchilla and squirrel monkey. Ann N Y Acad Sci 656:92-107.

Grasso C, Li Volsi G, Cataldo E, Manzoni D, Barresi M (2016) Effects of bicuculline application on the somatosensory responses of secondary vestibular neurons. Neuroscience 335:122-133.

Green BG, Akirav C (2010) Threshold and rate sensitivity of low-threshold thermal nociception. Eur J Neurosci 31:1637-1645.

Hiel H, Elgoyhen AB, Drescher DG, Morley BJ (1996) Expression of nicotinic acetylcholine receptor mRNA in the adult rat peripheral vestibular system. Brain Res 738:347-352.

Highstein SM, Holstein GR, Mann MA, Rabbitt RD (2014) Evidence that protons act as neurotransmitters at vestibular hair cell-calyx afferent synapses. Proc Natl Acad Sci U S A 111:5421-5426.

Holmes WR, Huwe JA, Williams B, Rowe MH, Peterson EH (2017) Models of utricular bouton afferents: role of afferent-hair cell connectivity in determining spike train regularity. J Neurophysiol 117:1969-1986.

Holt JC, Kewin K, Jordan PM, Cameron P, Klapczynski M, McIntosh JM, Crooks PA, Dwoskin LP, Lysakowski A (2015) Pharmacologically distinct nicotinic acetylcholine receptors drive efferent-mediated excitation in calyx-bearing vestibular afferents. J Neurosci 35:3625-3643.

Holt JC, Jordan PM, Lysakowski A, Shah A, Barsz K, Contini D (2017) Muscarinic acetylcholine receptors and M-currents underlie efferentmediated slow excitation in calyx-bearing vestibular afferents. J Neurosci 37:1873-1887.

Hübner PP, Khan SI, Migliaccio AA (2015) The mammalian efferent vestibular system plays a crucial role in the high-frequency response and short-term adaptation of the vestibuloocular reflex. J Neurophysiol 114: 3154-3165.

Hübner PP, Khan SI, Migliaccio AA (2017) The mammalian efferent vestibular system plays a crucial role in vestibulo-ocular reflex compensation after unilateral labyrinthectomy. J Neurophysiol 117:1553-1568.

Izzo AD, Richter CP, Jansen ED, Walsh JT Jr (2006) Laser stimulation of the auditory nerve. Lasers Surg Med 38:745-753.

Izzo AD, Walsh JT Jr, Ralph $\mathrm{H}$, Webb J, Bendett $\mathrm{M}$, Wells J, Richter $\mathrm{CP}$ (2008) Laser stimulation of auditory neurons: effect of shorter pulse duration and penetration depth. Biophys J 94:3159-3166.

Jordan PM, Fettis M, Holt JC (2015) Efferent innervation of turtle semicircular canal cristae: comparisons with bird and mouse. J Comp Neurol 523:1258-1280.

Kalluri R, Xue J, Eatock RA (2010) Ion channels set spike timing regularity of mammalian vestibular afferent neurons. J Neurophysiol 104:20342051.

Katz E, Elgoyhen AB, Gómez-Casati ME, Knipper M, Vetter DE, Fuchs PA, Glowatzki E (2004) Developmental regulation of nicotinic synapses on cochlear inner hair cells. J Neurosci 24:7814-7820.

Kingsley JD, Demchak T, Mathis R (2014) Low-level laser therapy as a treatment for chronic pain. Front Physiol 5:306.

Kong WJ, Guo CK, Zhang S, Hao J, Wang YJ, Li ZW (2005) The properties of ACh-induced BK currents in guinea pig type II vestibular hair cells. Hear Res 209:1-9.

Kong WJ, Cheng HM, van Cauwenberge P (2006) Expression of nicotinic acetylcholine receptor subunit alpha9 in type II vestibular hair cells of rats. Acta Pharmacol Sin 27:1509-1514.

Kong W, Egg G, Schrott-Fischer A, Hussl B (1997) Innervation of cholinergic vestibular efferent system in vestibular periphery of rats. J Tongji Med Univ 17:57-60, 64.

Lasker DM, Han GC, Park HJ, Minor LB (2008) Rotational responses of vestibular-nerve afferents innervating the semicircular canals in the C57BL/6 mouse. J Assoc Res Otolaryngol 9:334-348.

Lee C, Holt JC, Jones TA (2017) Effect of M-current modulation on mammalian vestibular responses to transient head motion. J Neurophysiol 118:2991-3006.

Leijon S, Magnusson AK (2014) Physiological characterization of vestibular efferent brainstem neurons using a transgenic mouse model. PLoS One 9:e98277.

Lim R, Kindig AE, Donne SW, Callister RJ, Brichta AM (2011) Potassium accumulation between type I hair cells and calyx terminals in mouse crista. Exp Brain Res 210:607-621.

Littlefield PD, Vujanovic I, Mundi J, Matic AI, Richter CP (2010) Laser stimulation of single auditory nerve fibers. Laryngoscope 120:2071-2082.

Lothet EH, Kilgore KL, Bhadra N, Bhadra N, Vrabec T, Wang YT, Jansen ED,
Jenkins MW, Chiel HJ (2014) Alternating current and infrared produce an onset-free reversible nerve block. Neurophotonics 1:011010.

Lothet EH, Shaw KM, Lu H, Zhuo J, Wang YT, Gu S, Stolz DB, Jansen ED, Horn CC, Chiel HJ, Jenkins MW (2017) Selective inhibition of smalldiameter axons using infrared light. Sci Rep 7:3275.

Luebke AE, Holt JC, Jordan PM, Wong YS, Caldwell JS, Cullen KE (2014) Loss of alpha-calcitonin gene-related peptide (alphaCGRP) reduces the efficacy of the vestibulo-ocular reflex (VOR). J Neurosci 34:10453-10458.

Luo J, Shen WL, Montell C (2017) TRPA1 mediates sensation of the rate of temperature change in Drosophila larvae. Nat Neurosci 20:34-41.

Lysakowski A, Minor LB, Fernández C, Goldberg JM (1995) Physiological identification of morphologically distinct afferent classes innervating the cristae ampullares of the squirrel monkey. J Neurophysiol 73:1270-1281.

Lysakowski A, Gaboyard-Niay S, Calin-Jageman I, Chatlani S, Price SD, Eatock RA (2011) Molecular microdomains in a sensory terminal, the vestibular calyx ending. J Neurosci 31:10101-10114.

Marlinski V, Plotnik M, Goldberg JM (2004) Efferent actions in the chinchilla vestibular labyrinth. J Assoc Res Otolaryngol 5:126-143.

Mathews MA, Murray A, Wijesinghe R, Cullen K, Tung VW, Camp AJ (2015) Efferent vestibular neurons show homogenous discharge output but heterogeneous synaptic input profile in vitro. PLoS One 10:e0139548.

Mathews MA, Camp AJ, Murray AJ (2017) Reviewing the role of the efferent vestibular system in motor and vestibular circuits. Front Physiol 8:552.

Meredith FL, Rennie KJ (2015) Zonal variations in $\mathrm{K}^{+}$currents in vestibular crista calyx terminals. J Neurophysiol 113:264-276.

Minor LB, Lasker DM (2009) Tonic and phasic contributions to the pathways mediating compensation and adaptation of the vestibulo-ocular reflex. J Vestib Res 19:159-170.

Parks XX, Contini D, Jordan PM, Holt JC (2017) Confirming a role for alpha9nAChRs and SK potassium channels in type II hair cells of the turtle posterior crista. Front Cell Neurosci 11:356.

Paxinos G, Franklin KBJ (2004) The mouse brain in stereotaxic coordinates. Amsterdam: Elsevier Academic.

Perachio AA, Kevetter GA (1989) Identification of vestibular efferent neurons in the gerbil: histochemical and retrograde labelling. Exp Brain Res 78:315-326.

Pérez C, Limón A, Vega R, Soto E (2009) The muscarinic inhibition of the potassium M-current modulates the action-potential discharge in the vestibular primary-afferent neurons of the rat. Neuroscience 158:16621674

Plotnik M, Marlinski V, Goldberg JM (2002) Reflections of efferent activity in rotational responses of chinchilla vestibular afferents. J Neurophysiol 88:1234-1244.

Poppi LA, Tabatabaee H, Drury HR, Jobling P, Callister RJ, Migliaccio AA, Jordan PM, Holt JC, Rabbitt RD, Lim R, Brichta AM (2018) AChinduced hyperpolarization and decreased resistance in mammalian type II vestibular hair cells. J Neurophysiol 119:312-325.

Purcell IM, Perachio AA (1996) Regional distributions of efferent neurons in the semicircular canals in the gerbil. Ann N Y Acad Sci 781:680-682.

Purcell IM, Perachio AA (1997) Three-dimensional analysis of vestibular efferent neurons innervating semicircular canals of the gerbil. J Neurophysiol 78:3234-3248.

Rabbitt RD, Brichta AM, Tabatabaee H, Boutros PJ, Ahn J, Della Santina CC, Poppi LA, Lim R (2016) Heat pulse excitability of vestibular hair cells and afferent neurons. J Neurophysiol 116:825-843.

Rajguru SM, Richter CP, Matic AI, Holstein GR, Highstein SM, Dittami GM, Rabbitt RD (2011) Infrared photostimulation of the crista ampullaris. J Physiol 589:1283-1294.

Ramachandran R, Lisberger SG (2006) Transformation of vestibular signals into motor commands in the vestibuloocular reflex pathways of monkeys. J Neurophysiol 96:1061-1074.

Regan D, Murray TJ, Silver R (1977) Effect of body temperature on visual evoked potential delay and visual perception in multiple sclerosis. J Neurol Neurosurg Psychiatry 40:1083-1091.

Richter CP, Bayon R, Izzo AD, Otting M, Suh E, Goyal S, Hotaling J, Walsh JT Jr (2008) Optical stimulation of auditory neurons: effects of acute and chronic deafening. Hear Res 242:42-51.

Rocha-Sanchez SM, Morris KA, Kachar B, Nichols D, Fritzsch B, Beisel KW (2007) Developmental expression of Kcnq4 in vestibular neurons and neurosensory epithelia. Brain Res 1139:117-125.

Rojas JC, Gonzalez-Lima F (2011) Low-level light therapy of the eye and brain. Eye Brain 3:49-67. 
Sadeghi SG, Minor LB, Cullen KE (2007a) Response of vestibular-nerve afferents to active and passive rotations under normal conditions and after unilateral labyrinthectomy. J Neurophysiol 97:1503-1514.

Sadeghi SG, Chacron MJ, Taylor MC, Cullen KE (2007b) Neural variability, detection thresholds, and information transmission in the vestibular system. J Neurosci 27:771-781.

Sadeghi SG, Goldberg JM, Minor LB, Cullen KE (2009a) Efferent-mediated responses in vestibular nerve afferents of the alert macaque. J Neurophysiol 101:988-1001.

Sadeghi SG, Goldberg JM, Minor LB, Cullen KE (2009b) Effects of canal plugging on the vestibuloocular reflex and vestibular nerve discharge during passive and active head rotations. J Neurophysiol 102:2693-2703.

Sadeghi SG, Pyott SJ, Yu Z, Glowatzki E (2014) Glutamatergic signaling at the vestibular hair cell calyx synapse. J Neurosci 34:14536-14550.

Saito Y, Takazawa T, Ozawa S (2008) Relationship between afterhyperpolarization profiles and the regularity of spontaneous firings in rat medial vestibular nucleus neurons. Eur J Neurosci 28:288-298.

Schwarz JR, Eikhof G (1987) Na currents and action potentials in rat myelinated nerve fibres at 20 and 37 degrees C. Pflugers Arch 409:569-577.

Sekirnjak C, du Lac S (2006) Physiological and anatomical properties of mouse medial vestibular nucleus neurons projecting to the oculomotor nucleus. J Neurophysiol 95:3012-3023.

Shapiro MG, Homma K, Villarreal S, Richter CP, Bezanilla F (2012) Infrared light excites cells by changing their electrical capacitance. Nat Commun 3:736.

Songer JE, Eatock RA (2013) Tuning and timing in mammalian type I hair cells and calyceal synapses. J Neurosci 33:3706-3724.

Straver DC, van den Berg LH, Franssen H (2011) Activity-dependent con- duction block in chronic inflammatory demyelinating polyneuropathy. J Neurol Sci 300:33-38.

Tsuchiya K, Kawatani M, Takeshige C, Matsumoto I (1994) Laser irradiation abates neuronal responses to nociceptive stimulation of rat-paw skin. Brain Res Bull 34:369-374.

Wakabayashi H, Hamba M, Matsumoto K, Tachibana H (1993) Effect of irradiation by semiconductor laser on responses evoked in trigeminal caudal neurons by tooth pulp stimulation. Lasers Surg Med 13:605-610.

Wang AK, Raynor EM, Blum AS, Rutkove SB (1999) Heat sensitivity of sensory fibers in carpal tunnel syndrome. Muscle Nerve 22:37-42.

Wang J, Chi FL, Xin Y, Regner MF (2013) The distribution of vestibular efferent neurons receiving innervation of secondary vestibular afferent nerves in rats. Laryngoscope 123:1266-1271.

Warr WB (1975) Olivocochlear and vestibular efferent neurons of the feline brain stem: their location, morphology and number determined by retrograde axonal transport and acetylcholinesterase histochemistry. J Comp Neurol 161:159-181.

Wersinger E, Fuchs PA (2011) Modulation of hair cell efferents. Hear Res 279:1-12.

Yan W, Chow R, Armati PJ (2011) Inhibitory effects of visible $650 \mathrm{~nm}$ and infrared $808 \mathrm{~nm}$ laser irradiation on somatosensory and compound muscle action potentials in rat sciatic nerve: implications for laser-induced analgesia. J Peripher Nerv Syst 16:130-135.

Yu XJ, Dickman JD, Angelaki DE (2012) Detection thresholds of macaque otolith afferents. J Neurosci 32:8306-8316.

Zhou T, Wang Y, Guo CK, Zhang WJ, Yu H, Zhang K, Kong WJ (2013) Two distinct channels mediated by $\mathrm{m} 2 \mathrm{mAChR}$ and alpha9nAChR co-exist in type II vestibular hair cells of guinea pig. Int J Mol Sci 14:8818-8831. 